OPEN ACCESS

Edited by:

Sanjay Prabhu Govindwar

Shivaji University, India

Reviewed by:

Vishwas Ananat Bapat,

Shivaji University, India

Ashutosh Singh,

University of Lucknow, India

*Correspondence:

Beidong Liu

beidong.liu@cmb.gu.se

Menggen Ma

mgen@sicau.edu.cn

${ }^{\dagger}$ These authors have contributed equally to this work

Specialty section: This article was submitted to

Microbiotechnology,

a section of the journal

Frontiers in Microbiology

Received: 21 January 2020 Accepted: 12 March 2020

Published: 15 April 2020

Citation:

Wang $H, L i$ Q, Peng Y, Zhang Z, Kuang X, Hu X, Ayepa E, Han X, Abrha GT, Xiang Q, Yu X, Zhao $K$,

Zou L, Gu Y, Li X, Li X, Chen Q, Zhang $X$, Liu B and Ma M (2020)

Cellular Analysis and Comparative Transcriptomics Reveal the Tolerance Mechanisms of Candida tropicalis

Toward Phenol.

Front. Microbiol. 11:544.

doi: 10.3389/fmicb.2020.00544

\section{Cellular Analysis and Comparative Transcriptomics Reveal the Tolerance Mechanisms of Candida tropicalis Toward Phenol}

\author{
Hanyu Wang ${ }^{1 \dagger}$, Qian Litt, Yuanyuan Peng ${ }^{1+}$, Zhengyue Zhang ${ }^{1 t}$, Xiaolin Kuang ${ }^{1}$, \\ Xiangdong $\mathrm{Hu}^{1}$, Ellen Ayepa ${ }^{1}$, Xuebing Han ${ }^{1}$, Getachew Tafere Abrha' ${ }^{1}$, Quanju Xiang ${ }^{2}$,

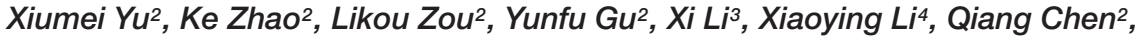 \\ Xiaoping Zhang ${ }^{2}$, Beidong Liu $^{5,6 *}$ and Menggen $\mathrm{Ma}^{1,2 *}$

\begin{abstract}
${ }^{1}$ Institute of Resources and Geographic Information Technology, College of Resources, Sichuan Agricultural University, Chengdu, China, ${ }^{2}$ Department of Applied Microbiology, College of Resources, Sichuan Agricultural University, Chengdu, China, ${ }^{3}$ College of Landscape Architecture, Sichuan Agricultural University, Chengdu, China, ${ }^{4}$ School of Forestry and Life Science, Chongqing University of Arts and Sciences, Chongqing, China, ${ }^{5}$ Department of Chemistry and Molecular Biology, University of Gothenburg, Göteburg, Sweden, ${ }^{6}$ State Key Laboratory of Subtropical Silviculture, School of Forestry and Biotechnology, Zhejiang A\&F University, Hangzhou, China
\end{abstract}

Phenol is a ubiquitous pollutant and can contaminate natural water resources. Hence, the removal of phenol from wastewater is of significant importance. A series of biological methods were used to remove phenol based on the natural ability of microorganisms to degrade phenol, but the tolerance mechanism of phenol-degraded strains to phenol are not very clear. Morphological observation on Candida tropicalis showed that phenol caused the reactive oxygen species (ROS) accumulation, damaging the mitochondrial and the endoplasmic reticulum. On the basis of transcriptome data and cell wall susceptibility analysis, it was found that $C$. tropicalis prevented phenol-caused cell damage through improvement of cell wall resistance, maintenance of high-fidelity DNA replication, intracellular protein homeostasis, organelle integrity, and kept the intracellular phenol concentration at a low level through cell-wall remodeling and removal of excess phenol via MDR/MXR transporters. The knowledge obtained will promote the genetic modification of yeast strains in general to tolerate the high concentrations of phenol and improve their efficiency of phenol degradation.

Keywords: Candida tropicalis, morphological observation, phenol, reactive oxygen species (ROS), tolerance mechanism, transcriptome

\section{INTRODUCTION}

Phenol, one of the aromatic compounds, is composed of the hydroxyl group and the benzene ring and is applied as the main material for the production of pesticides, antiseptics, slimicides, and medicinal preparations (Mishra and Kumar, 2017) but contaminate the natural water resources. It was found that the inhalation, skin contact, and ingestion of phenol can lead to damages of central nervous system (CNS) disorders and the kidneys (Mahgoub et al., 2014; Mishra and Kumar, 2017). 
Hence, the removal of phenol from wastewater is quite important for environmental protection and for the human health. A series of physicochemical methods have been explored and applied to remove phenol from the wastewater (Pinto et al., 2005; Matjie and Engelbrecht, 2007; Busca et al., 2008). However, the energy consumption, high cost, hazardous byproducts production, and poor efficiency of these methods limited their widespread applications (Banerjee and Ghoshal, 2011). The natural ability of microorganisms to degrade phenol, and a few biological treatments of phenol are explored and found to be more efficient than physicochemical methods (Jiang et al., 2005; Banerjee and Ghoshal, 2011; Yoneda et al., 2016). It is a challenge for the wide applications of biological methods that these compounds are toxic to microbial cells, can prolong the lag phase, and reduce the phenol degradation efficiency (Heipieper et al., 1991). Additionally, phenol can penetrate the cellular membrane and cause the increased membrane permeability and decreased membrane lipid-to-protein ratios (Heipieper et al., 1991), and can cause dysfunction of organelles. The membrane disruption of mitochondria induced by phenol can induce the accumulation of excessive ROS (Klaunig et al., 2011), which interact with proteins, DNA, and lipids, and then result in damage of cytoskeleton, DNA mutagenesis, and the programmed cell death (Ibraheem and Ndimba, 2013). Hence, the phenol tolerance of microorganisms is vital to the effective degradation of phenol as well as screening and isolation of phenol-tolerant strains and deciphering of their tolerance mechanisms are immensely important.

Although recent studies found that chromatin remodeling, efflux of toxic compounds, and aggregation of lipopolysaccharides on the outer cell membrane could increase the resistance of microorganisms to phenolic aldehydes derived from lignocellulose pretreatment ( $\mathrm{Gu}$ et al., 2015; Yi et al., 2015), a part of the above mechanisms might be associated with the aldehyde tolerance. Another study focused on $R$. opacus PD630 found that phenol tolerance mainly involved the import and degradation of extracellular phenol (Yoneda et al., 2016), but the understanding of the tolerance mechanisms, not degradation mechanisms, of strains to phenol is not very clear.

C. tropicalis can not only utilize a range of carbon sources but also produce a range of biological products, including bioethanol, xylitol, and long-chain dicarboxylic acids (Horitsu et al., 1992; Kurihara et al., 1992; Sampaio, 1999). Additionally, C. tropicalis can tolerate high concentrations of phenol, salts, heat, furfural, and acetic acid (Adav et al., 2007; Wang et al., 2015). The genome of $C$. tropicalis has been completely sequenced (Butler et al., 2009), enabling to explore the molecular mechanisms of C. tropicalis in different conditions and considered as one of the promising strains for deciphering the tolerance mechanisms of microorganisms to phenol. Previous studies on the tolerance mechanisms of $C$. tropicalis to phenol have been focused on the degradation of phenol by biodegradation (Jiang et al., 2005; Klaunig et al., 2011), but not the molecular and cellular mechanisms. In this study, pre-cultured cells of C. tropicalis strain SHC-03 were treated with phenol in order to explore the above mechanisms via fluorescence microscopy and comparative transcriptomics.

\section{MATERIALS AND METHODS}

\section{Yeast Growth Conditions and Reagents}

C. tropicalis SHC-03, isolated from a winery in She Hong, was grown in YPD medium (w/v, 1\% yeast extract, $2 \%$ peptone, and $2 \%$ glucose) and in YPD medium supplemented with 0.5, 1.0, 2.0, and $3.0 \mathrm{~g} / \mathrm{L}$ phenol with $200 \mathrm{rpm}$ shaking at $30^{\circ} \mathrm{C}$. The initial cell count in the culture was adjusted to $\sim 1.0 \times$ absorbance value (optical density at $600 \mathrm{~nm}$ wavelength, $\mathrm{OD}_{600}$ ). With nonphenol-treated culture as control, the pre-cultures were cultivated in YPD medium overnight, then harvested by centrifugation at $4,000 \mathrm{rpm}$ for $3 \mathrm{~min}$ at $4^{\circ} \mathrm{C}$, and inoculated into $50 \mathrm{~mL}$ flasks with phenol-added YPD medium. Aliquots of cells and supernatant were harvested for analysis at various time points from 0 to $72 \mathrm{~h}$. Cell density $\left(\mathrm{OD}_{600}\right)$ of the cultures was determined by using a UV-2802 spectrophotometer (Unico, NJ, United States). Media ingredients were purchased from Sigma-Aldrich (St. Louis, MO, United States) or Sangon Biotech (Shanghai, China).

\section{Determination of Phenol Degradation Rate}

The concentration of residual phenol was determined by the 4-aminoantipyrine spectrophotometric method. The reaction among phenol, 4-aminoantipyrine and potassium ferricyanide will develop a red color under alkaline conditions which can be measured by reading the absorbance at $510 \mathrm{~nm}\left(\mathrm{OD}_{510}\right)$.

\section{qRT-PCR Assays}

To confirm the accuracy of results from RNA-seq, the qRT-PCR assay of the isolated mRNA for RNA-seq were implemented on a Mastercycler ${ }^{\circledR}$ EP Realplex system (Eppendorf, Hamburg, Germany), using the procedures reported previously (Anders and Huber, 2010). A FastQuant RT Kit (With gDNase) and a Real Master Mix (SYBR Green) Kit (Tiangen Biotech Co., Ltd.) were respectively exploited to synthesize the first-strand cDNA and quantitative PCR reactions. Before qRT-PCR reactions were carried out, a calibrated messenger RNA (mRNA) control mix, which was gifted by Z. Lewis Liu (Bioenergy Research, NCAURARS, US Department of Agriculture, Peoria, IL, United States), was integrated into the reaction system as a reference. Using online software of primer $3^{1}$, the primers of the selected genes were designed for qRT-PCR assay (Supplementary Table S1). In the $\mathrm{qRT}$-PCR reactions, three biological replicates and three technical replicates were performed, and the acquired data was analyzed using the developed methods (Liu and Slininger, 2007).

\section{RNA-Seq and Analysis}

After the pre-cultured cells of C. tropicalis SHC-03 were transferred into the YPD mediums with different concentration of phenol, the phenol-treated cells and the non-phenol-treated cells were obtained at $3 \mathrm{~h}$ for RNA-Seq. RNA-Seq was conducted by Biomarker Technology Co. Ltd. (Beijing, China) with HiseqPE150 (Illumina, Inc., San Diego, CA United States). Based on the sequence of C. tropicalis MYA-3404 as reference genome,

\footnotetext{
${ }^{1}$ http://bioinfo.ut.ee/primer3-0.4.0/primer3/
} 
we analyzed the raw data by the BMKCloud cloud server ${ }^{2}$. The gene expression levels were analyzed using fragments per kilobase of the transcript per million mapped (FPKM) method (Florea et al., 2013). Differential expression analysis of two samples with three biological replicates was performed using the DEGseq $\mathrm{R}$ package (Anders and Huber, 2010) in a threshold criterion of the value of $\mid \log _{2}$ (fold change) $\mid \geq 1$ (FDR $\left.<0.05\right)$. The annotations of differentially expressed genes (DEGs) were performed by the GO (Ashburner et al., 2000) and KEGG (Kanehisa et al., 2004) databases. We performed the statistical tests to identify the DEGs enriched in different KEGG pathways using KOBAS software (Mao et al., 2005).

\section{Fluorescence Microscopy and Cellular Analysis}

The fluorescence microscopy, an Axio Imager A2 microscope (Carl Zeiss AG, Oberkochen, Germany) equipped with DIC, GFP, Rhod and DAPI filter lens, and different dyes, including $2^{\prime}, 7^{\prime}$-dichlorofluorescein diacetate (DCFH-DA), diaminophenylindole (DAPI), Mito Tracker ${ }^{\mathrm{TM}}$ Green FM, ER-Tracker ${ }^{\mathrm{TM}}$ Red, and Yeast Vacuole Membrane Marker MDY-64, were used to observe the integrity of the cellular structures to evaluate the accumulation of ROS, nuclear chromatin disorganization, mitochondrial membrane damage, endoplasmic reticulum membrane damage, and vacuole membrane damage. The processing procedure is carried out according to the corresponding experimental instruction, respectively (Supplementary Material 2). Before the harvested cells were stained by various dyes, all the reagents and buffers have been preheated at $30^{\circ} \mathrm{C}$. To ensure the accuracy of experiment results, at least 100 cells were examined on each bright-field image.

\section{Determination of Intracellular SOD, CTT, GPX, GLR Activity, and GSH Content}

After the pre-cultured cells of C. tropicalis SHC-03 were transferred into the YPD mediums with different concentration of phenol, the phenol-treated cells and the non-phenol-treated cells were harvested at 3,6 , and $9 \mathrm{~h}$ for determination of intracellular SOD, GPX, CTT, GLR activity, and GSH content. The corresponding values was detected using SOD, GPX, CTT, GLR, and GSH assay kit purchased from Solarbio (Beijing, China) according to the manufacturer's instructions, respectively.

\section{Cell Wall Susceptibility Analysis}

To understand the structural changes of cell wall induced by phenol, we performed the lyticase-dependent susceptibility analysis (Teixeira et al., 2009). Lyticase, a $\beta$-1,3-glucanase from Arthrobacter luteus, was purchased from Sigma-Aldrich (St. Louis, MO, United States). $10^{7}$ cells, harvested from different mediums with or without phenol, were washed twice with ultrapure water and resuspended in $2.0 \mathrm{~mL}$ PBS pH 7.0. Sixty microliters of a $2 \mathrm{mgmL}$ lyticase was mixed into the cell suspensions, the decrease in the $\mathrm{OD}_{600}$ of each cell suspension was detected from 0 to $4 \mathrm{~h}$.

${ }^{2}$ http://www.biocloud.net

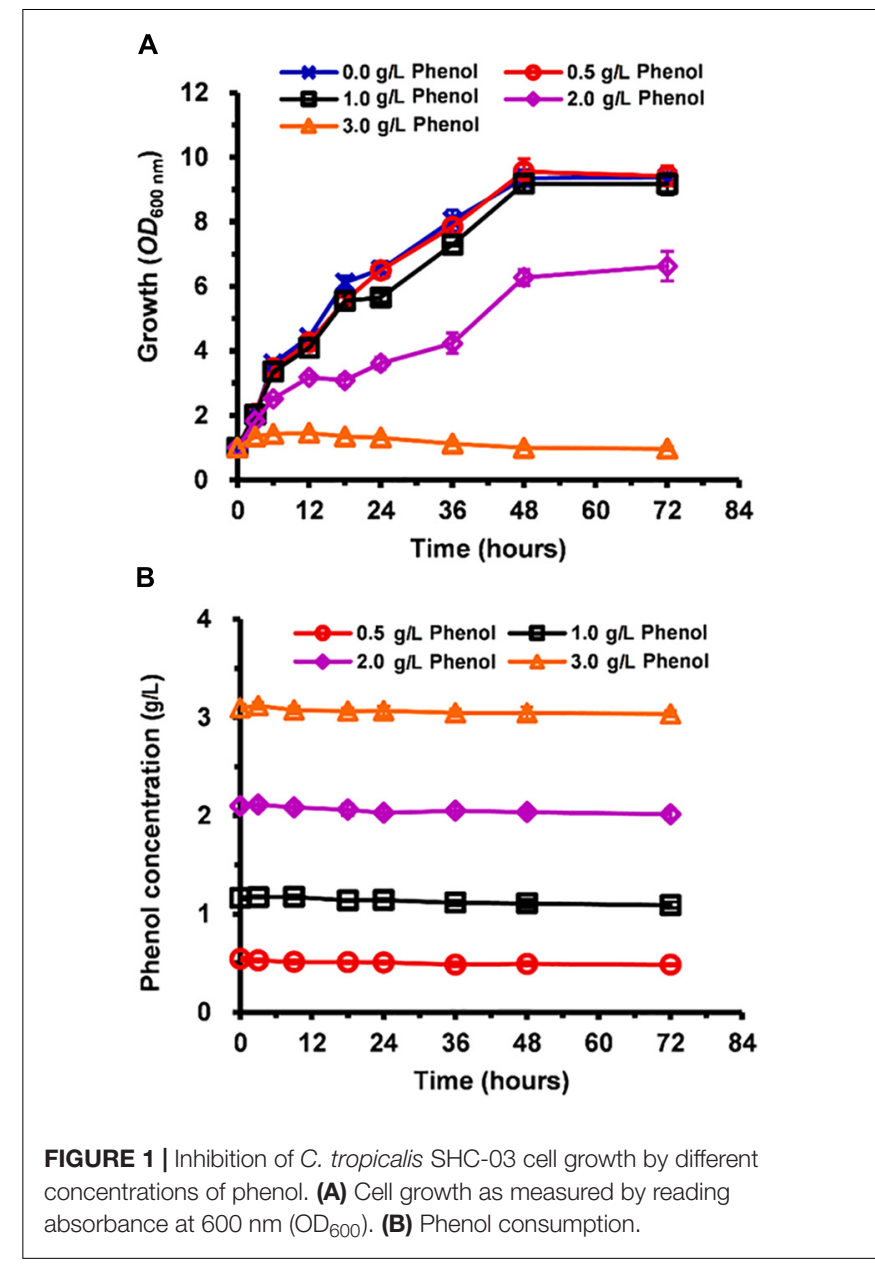

\section{RESULTS}

\section{Growth and Phenol Consumption in Phenol-Supplemented Medium}

Compared with the non-phenol-treated culture, the cell growth of phenol-treated C. tropicalis SHC-03 was slightly inhibited when the media contained 0.5 and $1.0 \mathrm{~g} / \mathrm{L}$ phenol (Figure 1A). However, in the presence of 2.0 and $3.0 \mathrm{~g} / \mathrm{L}$ phenol, cell growth was hindered by $\sim 40$ and $100 \%$, respectively (Figure 1A). The growth rate of cells treated with $2.0 \mathrm{~g} / \mathrm{L}$ phenol remained at a low level from 3 to $24 \mathrm{~h}$, implying that phenol influenced cell growth (Figure 1A). However, the cells returned to normal levels of growth after treatment for $24 \mathrm{~h}$ in the presence of $2.0 \mathrm{~g} / \mathrm{L}$ phenol. The 4-aminoantipyrine spectrophotometric method revealed no significant change in the concentration of phenol in any of the treatments at $0-72 \mathrm{~h}$ (Figure 1B), which indicated that the phenol degradation mechanism of C. tropicalis SHC-03 was not activated in these conditions. To summarize, a range of tolerance mechanisms for protecting cells from the toxic damage of phenol were activated during the lag phase and RNA-seq technology and cytological techniques demonstrated the potential tolerance mechanisms of C. tropicalis to phenol. 


\section{RNA-Seq, Transcriptomic Analysis, and qRT-PCR Assays}

After incubation with or without phenol for $3 \mathrm{~h}$, the cells were harvested for RNA-seq. Sequence reads data were archived at NCBI sequence read archive (SRA) with Accession Number PRJNA591802. The quality-control test results showed that the quality score $\left(\mathrm{Q}_{30}\right)$, clean data, and sequencing depth of each sample were, respectively, more than $94 \%, 4 \mathrm{~Gb}$, and $675 \times$ (Supplementary Table S2), which indicated a high level of accuracy for the RNA-seq results. To mitigate errors induced by biological variability between the samples, three biological replicates were used for the RNA-seq. The classification of the groups receiving different concentrations of phenol have been illustrated in Figure 2A, the correlations between T01, T06, T09 and their corresponding biological replicates were relatively low. To guarantee reliability and accuracy of the results from the differential expression analysis, T01, T06, and T09 were eliminated (Figure 2B).

The expression pattern of the $0.5 \mathrm{~g} / \mathrm{L}$ phenol group was highly consistent with that of the control group; only 39 genes and 40 genes showed up- and down-regulated expression, respectively, with twofold changes in the $0.5 \mathrm{~g} / \mathrm{L}$ phenol group compared with the control (Figures 2D,E). In contrast, for the 1.0 and $2.0 \mathrm{~g} / \mathrm{L}$ phenol groups, 353 and 1,985 genes showed altered expression levels, respectively (Figure 2C). Among these genes, 215 and 1,050 genes were identified as up-regulated genes in the 1.0 and $2.0 \mathrm{~g} / \mathrm{L}$ phenol groups, respectively (Figure 2D), and 138 and 935 genes, respectively, were repressed by phenol (Figure 2E).

In this study, 21 differentially expressed genes in response to $1.0 \mathrm{~g} / \mathrm{L}$ phenol were selected for the accuracy of the results from RNA-seq through a qRT-PCR assay. The criterion for gene selection was a combination of high-low gene expression level (FPKM) and absolute value of $\log _{2}$ (fold change). Through comparison and analysis, the expression levels of 18 of 21 genes $(\sim 85 \%)$ were consistent in the trend of up- and down-regulation (Figure 2F). Of the other three genes, inconsistent with the data from RNA-seq, two displayed lower absolute values of $\log _{2}$ (fold change) (Figure 2F). The results from RNA-Seq showed high accuracy, which contributed to the exploration of the phenol tolerance mechanism utilized by $C$. tropicalis.

\section{Accumulation and Scavenging of Reactive Oxygen Species (ROS) in Cells}

In order of increasing damage, to phenol stress, mitochondrial membrane showed different types of morphologies these were: tubular, fragmented, aggregated shapes, and necrotic (Figure 3A). At $3 \mathrm{~h}$, cells grown in media containing 0.0 and $0.5 \mathrm{~g} / \mathrm{L}$ phenol displayed tubular and fragmented mitochondria, while cells grown in media containing 2.0 and $3.0 \mathrm{~g} / \mathrm{L}$ phenol displayed aggregated and necrotic mitochondria (Figure 3C). In contrast, at $9 \mathrm{~h}$, only $3 \%$ of the non-phenol-treated cells appeared to be necrotic. At the same time point, among cells grown in $0.5 \mathrm{~g} / \mathrm{L}$ phenol, the percentage of cells with aggregated and necrotic mitochondria remained at a low level (Figure 3C). At $18 \mathrm{~h}$, cells with tubular mitochondria were no longer seen in cells grown in media with or without phenol. In addition, compared with the results at 3 and $9 \mathrm{~h}$, the distribution of cells containing aggregated mitochondria increased tremendously, with $95 \%$ of the yeast cells cultured in $1.0 \mathrm{~g} / \mathrm{L}$ phenol showing aggregated mitochondria at $18 \mathrm{~h}$. Furthermore, in cells cultured in 2.0 and $3.0 \mathrm{~g} / \mathrm{L}$ phenol, the proportion of necrotic cells increased to 33 and $58 \%$ at $18 \mathrm{~h}$, respectively (Figure $3 \mathrm{C}$ ). In summary, the ratio of mitochondrial deformation increased with the elevation of phenol concentration and treatment duration.

As most of the exogenous ROS were produced by damaged mitochondria (Klaunig et al., 2011), ROS accumulation of the treated and untreated cells was detected. The percentage of cells staining positive for ROS was considered to be representative of severity of oxidative stress (Figure 3B). Cultures in media containing 2.5, 5.0, and 7.5 mM hydrogen peroxide served as the positive controls for ROS (Figure 3D). In the medium without phenol, at 3 and $9 \mathrm{~h}$ after treatment, 5.6 and $6.5 \%$ of the cells exhibited a positive ROS signal, respectively (Figure 3D). At $3 \mathrm{~h}, 9.1,10.2,30.3$, and $42.1 \%$ of cells stained positive for ROS when $0.5,1.0,2.0$, and $3.0 \mathrm{~g} / \mathrm{L}$ phenol were present, respectively (Figure 3D), showing that the proportion of cells with ROS increased with increasing phenol concentration. At $9 \mathrm{~h}$, the percent of cells staining positive for accumulated ROS was 5.7, $12.8,11.6$, and $100.0 \%$, respectively (Figure 3D). The above results implied that the accumulation of ROS reached its peak $3 \mathrm{~h}$ after the treatment, while the accumulation of excessive ROS at this time might cause damage to DNA, proteins, and lipids (Gourlay and Ayscough, 2005; Perrone et al., 2008; Rowe et al., 2008), and that the intracellular ROS were eliminated by several molecular mechanisms between 3 and $9 \mathrm{~h}$ after the treatment.

Based on the transcriptome data, we found that the expression levels of most of these genes were not significantly up-regulated against $0.5,1.0$, and $2.0 \mathrm{~g} / \mathrm{L}$ phenol (Supplementary Table S3). Among these genes, CTRG_04448, CTRG_04203, CTRG_01769, CTRG_00610, and CTRG_05111 exhibited 4.3-, 2.3-, 2.1-, 4.0-, and 3.2-fold down-regulation, and CTRG_03986, CTRG_00152, CTRG_06042, and CTRG_02189 displayed 3.0-, 2.5-, 2.1-, and 2.6-fold up-regulation when exposed to $2.0 \mathrm{~g} / \mathrm{L}$ phenol (Supplementary Table S3). In addition, one of these genes, CTRG_00142, displayed 2.1-fold up-regulation when exposed to $1.0 \mathrm{~g} / \mathrm{L}$ phenol. The transcriptome data demonstrated that the enzymatic antioxidant defense systems would not be significantly activated for scavenging excessive ROS at $3 \mathrm{~h}$. In contrast, the above results from the determination of ROS showed that the excessive ROS in the phenol-treated cells were scavenged between 3 and $9 \mathrm{~h}$ (Figure 3D).

The enzyme activity assays was carried out for SOD, CTT, and GPX in the phenol-treated and non-phenol-treated cells which showed that, at $3 \mathrm{~h}$, the enzyme activity of intracellular SOD increased dramatically along with increasing phenol concentration (Figure 4B). The SOD activity of cells treated with $2.0 \mathrm{~g} / \mathrm{L}$ phenol was significantly higher after $6 \mathrm{~h}$ than that of the cells treated with $0.0,0.5$, and $1.0 \mathrm{~g} / \mathrm{L}$ phenol, but the SOD activity in cells treated with $3.0 \mathrm{~g} / \mathrm{L}$ phenol was considerably lower (Figure 4B). The SOD activities of all the treatments were lower at $6 \mathrm{~h}$ than those of the corresponding treatments at $3 \mathrm{~h}$. A few samples exhibited any SOD activity at $9 \mathrm{~h}$ (Figure $\mathbf{4 B}$ ). Since GPX and CTT are the key enzymes for the reduction of 


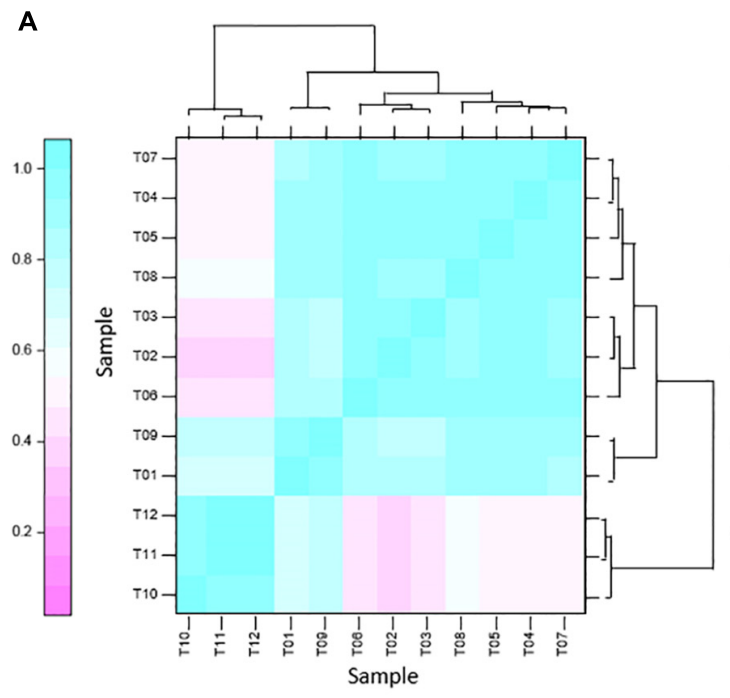

C
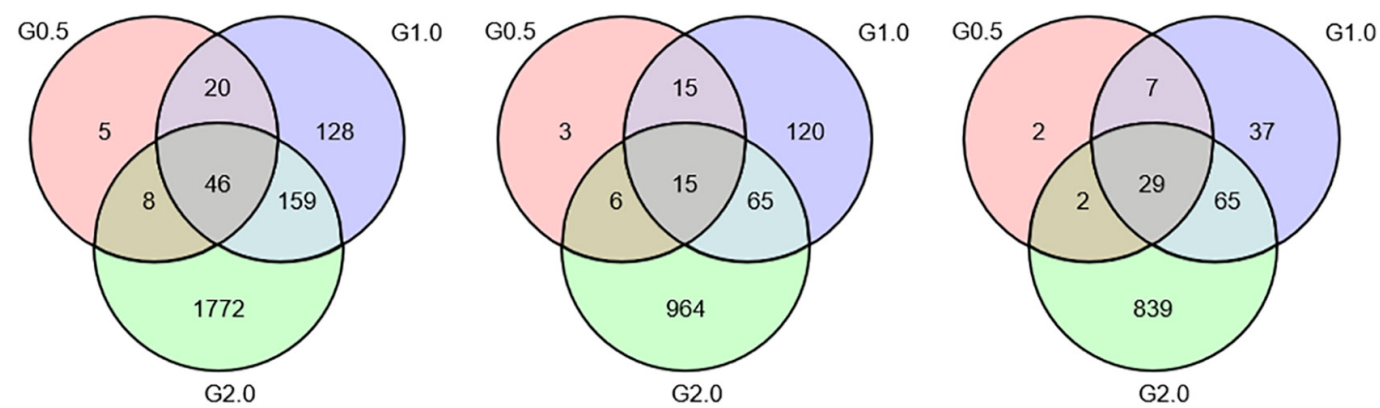
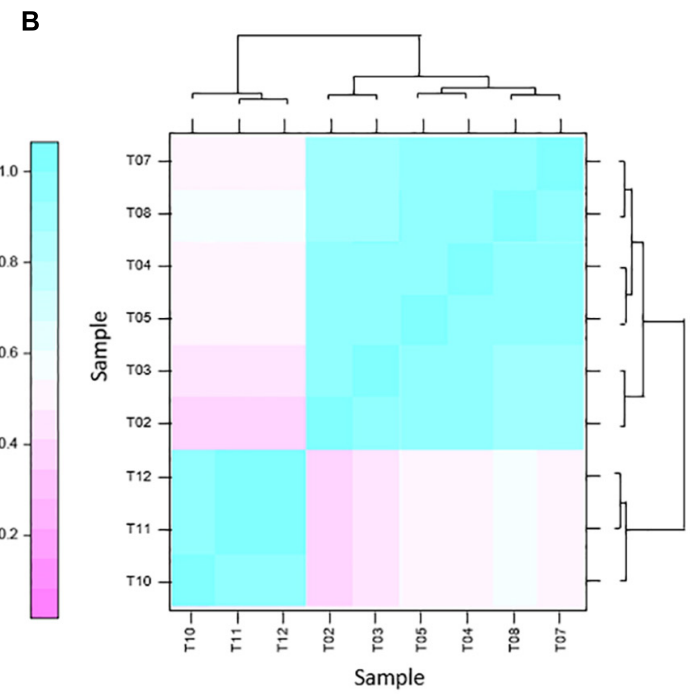

E

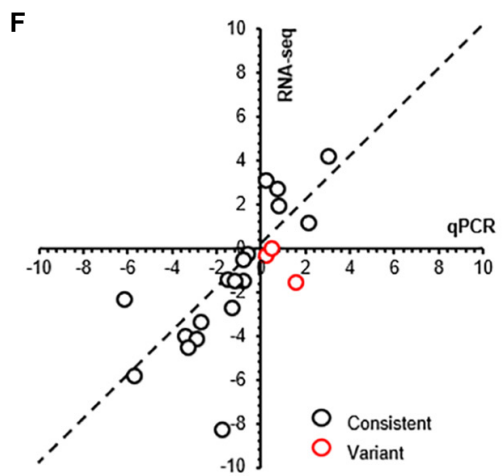



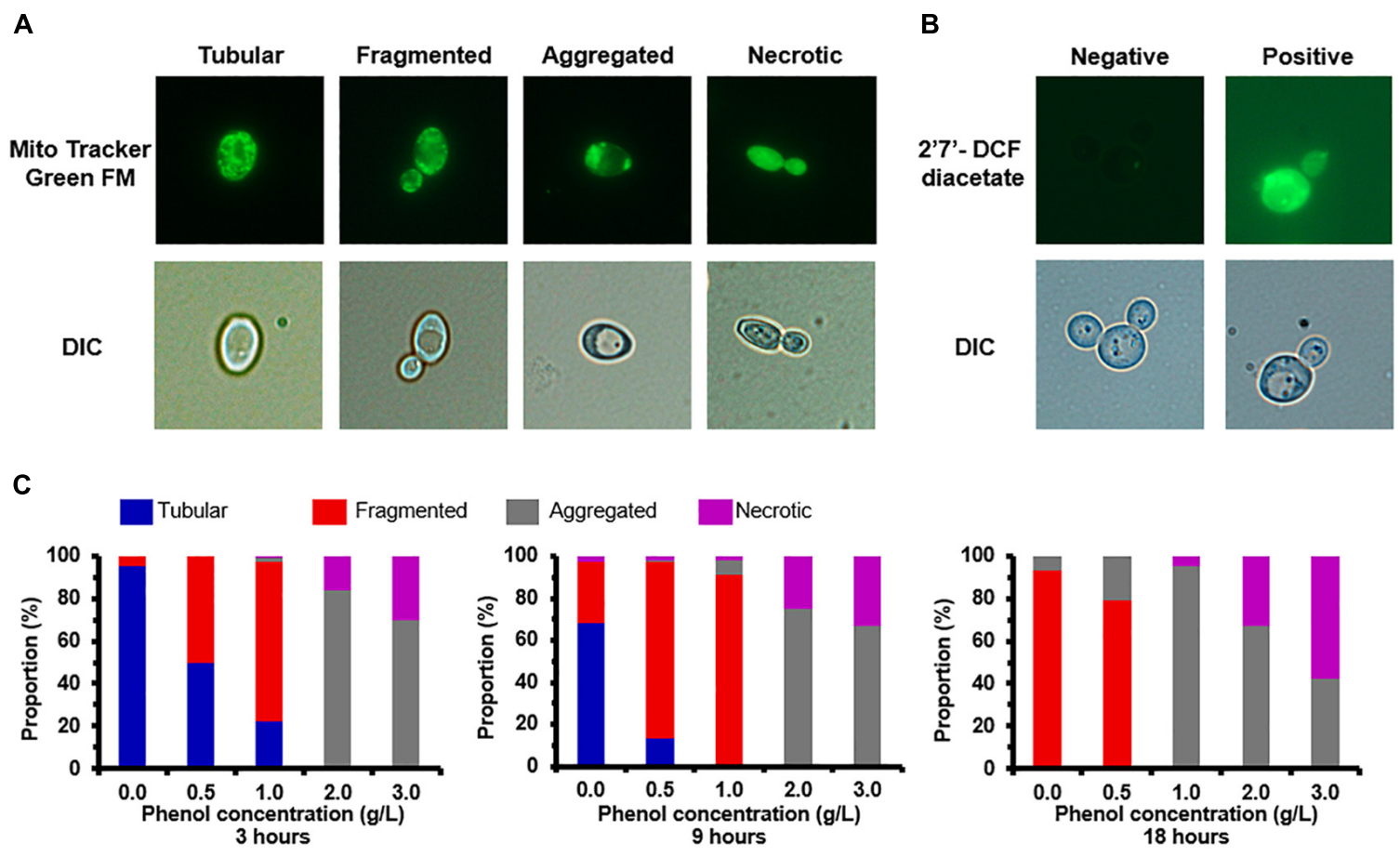

D

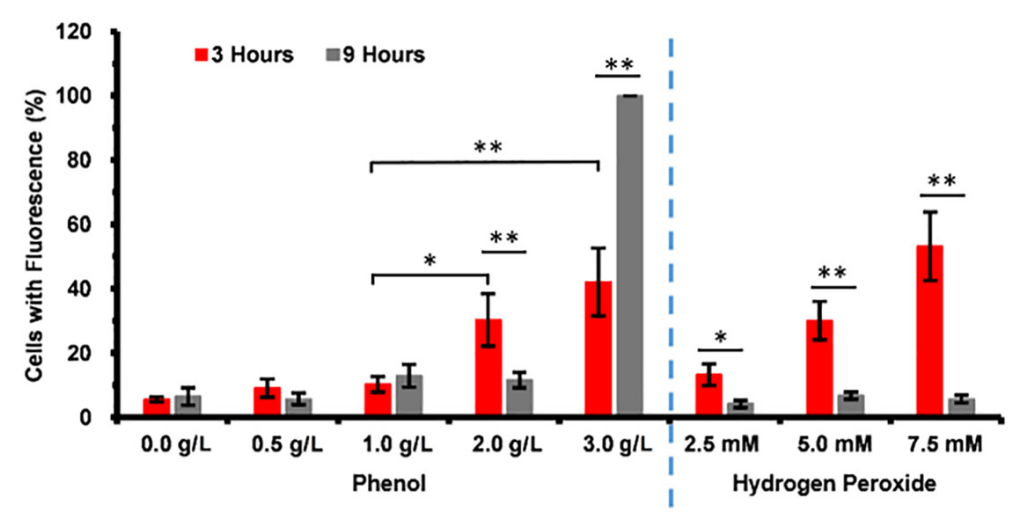

FIGURE 3 | Mitochondrial membrane damage and accumulation of reactive oxygen species (ROS) caused by phenol. Representative images of cells stained with the mitochondria-specific dye Mito Tracker ${ }^{\mathrm{TM}}$ Green FM and ROS indicator dye $2^{\prime}, 7^{\prime}$-dichlorofluorescein diacetate (DCFH-DA) are shown in the top column, and images taken using a differential interference contrast (DIC) lens are shown in the bottom column. (A) Morphological structure analysis of mitochondria.

(B) Accumulation analysis of ROS. (C) Percentage of cells at each concentration of phenol that displayed tubular, fragmented, and aggregated mitochondria, as well as necrotic, at 3, 9, and $18 \mathrm{~h}$. (D) Percentage of cells at each concentration of phenol and hydrogen peroxide that stained positive for ROS by DCFH-DA at 3 and $9 \mathrm{~h}$, with cultures in medium containing $2.5,5.0$, and $7.5 \mathrm{mM}$ hydrogen peroxide as positive controls for $\mathrm{ROS} .{ }^{*} p<0.05 ;{ }^{* *} p<0.01$ indicates significant differences. The data represent averages of three experiments. At least 100 cells were examined on each bright-field image.

$\mathrm{H}_{2} \mathrm{O}_{2}$, activities of both of the two enzymes were assayed. We found no significant differences in GPX activity in any of the treatments at $3 \mathrm{~h}$. However, cells treated with $1.0 \mathrm{~g} / \mathrm{L}$ phenol exhibited an increase in GPX activity at $9 \mathrm{~h}$, and cells treated with $2.0 \mathrm{~g} / \mathrm{L}$ phenol exhibited an increase in GPX activity at 6 and $9 \mathrm{~h}$. At both 6 and $9 \mathrm{~h}$, cells treated with $3.0 \mathrm{~g} / \mathrm{L}$ phenol had lost their GPX activity almost completely (Figure 4C). These results indicated that GPX activity significantly increased in cells treated with 1.0 and $2.0 \mathrm{~g} / \mathrm{L}$ phenol after 6 and $9 \mathrm{~h}$, but that the high concentration of phenol $(3.0 \mathrm{~g} / \mathrm{L}$ phenol) caused the loss of cellular GPX activity at $6 \mathrm{~h}$. The enzyme activity assays demonstrated no CTT activity in either phenol-treated or nonphenol-treated cells at the different processing times (data not shown). In addition, it has been found that high GLR activity and high GSH content can support high catalytic efficiency of GPX, which could protect the cells against ROS (Gill et al., 2013). In the present study, the enzyme activity of intracellular GLR was found to increase with phenol concentration at different processing times, except in those cells treated with $3.0 \mathrm{~g} / \mathrm{L}$ phenol, at 6 and $9 \mathrm{~h}$ (Figure 4D). From the viewpoint of processing time, the 

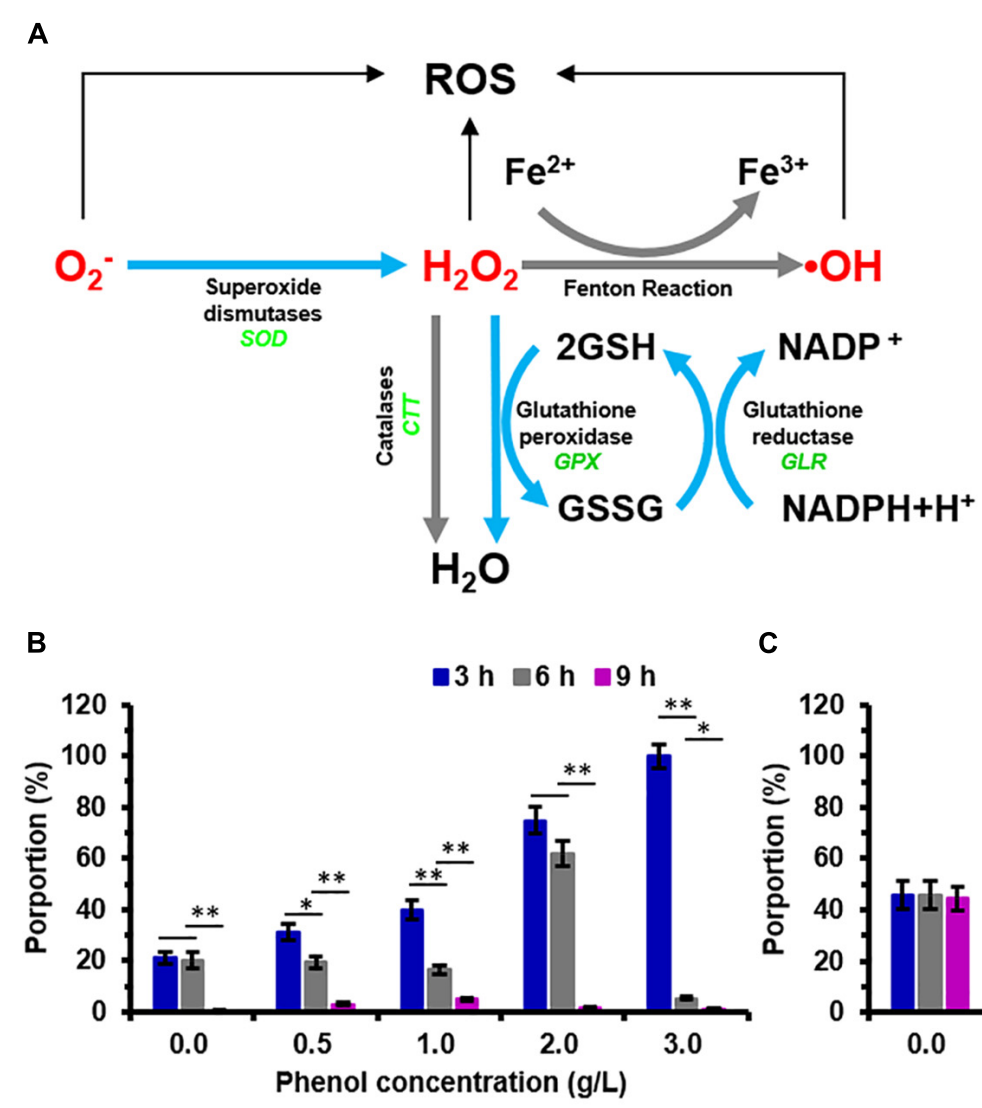

C

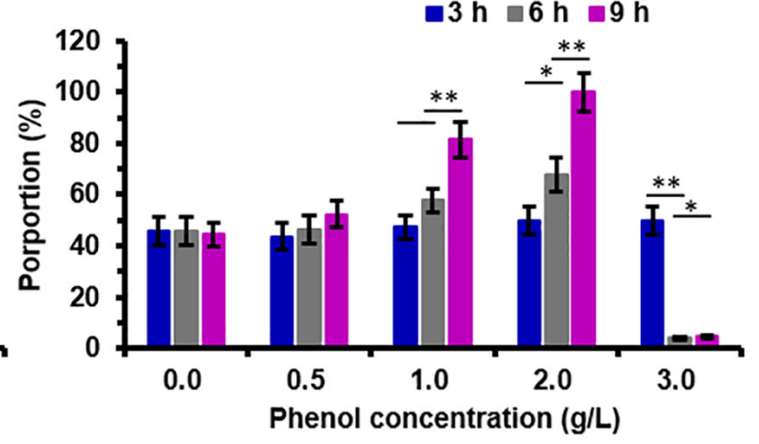

D

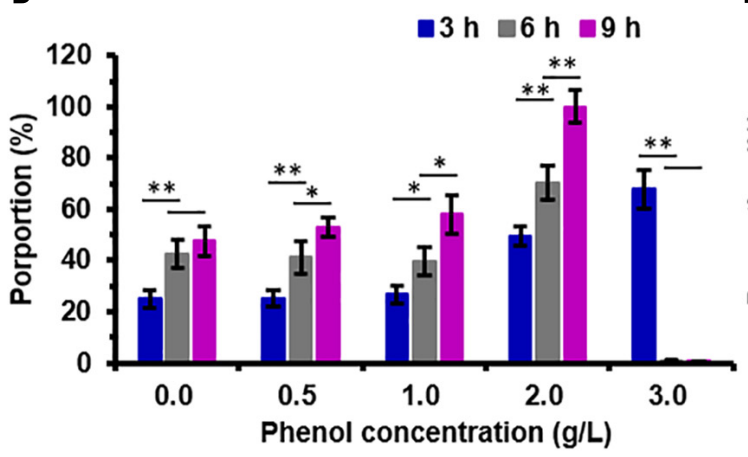

E

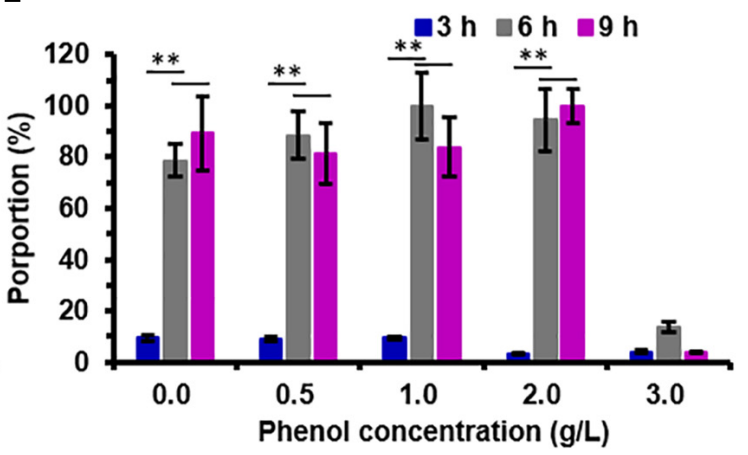

FIGURE 4 | Pathway for reactive oxygen species (ROS) scavenging in C. tropicalis SHC-03 and the change in activity of ROS-related enzymes after treatment with phenol. (A) The pathway shows the scavenging of reactive oxygen species (ROS) catalyzed by enzymatic antioxidant defense systems containing SOD, GPX, CTT, GLR, and GSH. (B-E) Activities of (B) SOD, (C) GPX, (D) GLR, and (E) GSH after treatments with 0.0-3.0 g/L phenol for 3, 6, and 9 h. ${ }^{*} p<0.05$; ${ }^{* *} p<0.01$ indicates significant differences.

cellular GLR activity after treatment for $9 \mathrm{~h}$ was higher than that after 3 and $6 \mathrm{~h}$ in the presence of $0.0-2.0 \mathrm{~g} / \mathrm{L}$ phenol. However, no GLR activity could be detected in cells treated with $3.0 \mathrm{~g} / \mathrm{L}$ phenol, at either 6 or $9 \mathrm{~h}$ (Figure 4D). The GSH content of cells treated with 2.0 and $3.0 \mathrm{~g} / \mathrm{L}$ phenol was lower than that in cells treated with less than $2.0 \mathrm{~g} / \mathrm{L}$ phenol at $3 \mathrm{~h}$. However, after $3 \mathrm{~h}$, the GSH content of cells treated with $0.0-2.0 \mathrm{~g} / \mathrm{L}$ phenol rose rapidly after 6 and $9 \mathrm{~h}$, and remained at a high level (Figure 4E). The GSH content remained at the same level in the presence of different concentrations of phenol after treatment for 6 and $9 \mathrm{~h}$, except in the $3.0 \mathrm{~g} / \mathrm{L}$ phenol group (Figure $4 \mathrm{E}$ ).

\section{Damage to Chromatin and Protection of Chromosomal DNA}

The investigation on the chromatin damage caused by phenol showed that the structurally abnormal nuclear chromatin appeared larger and more diffuse, while the normal chromatin 
A

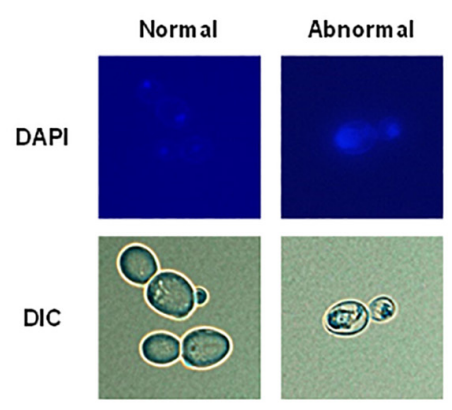

C

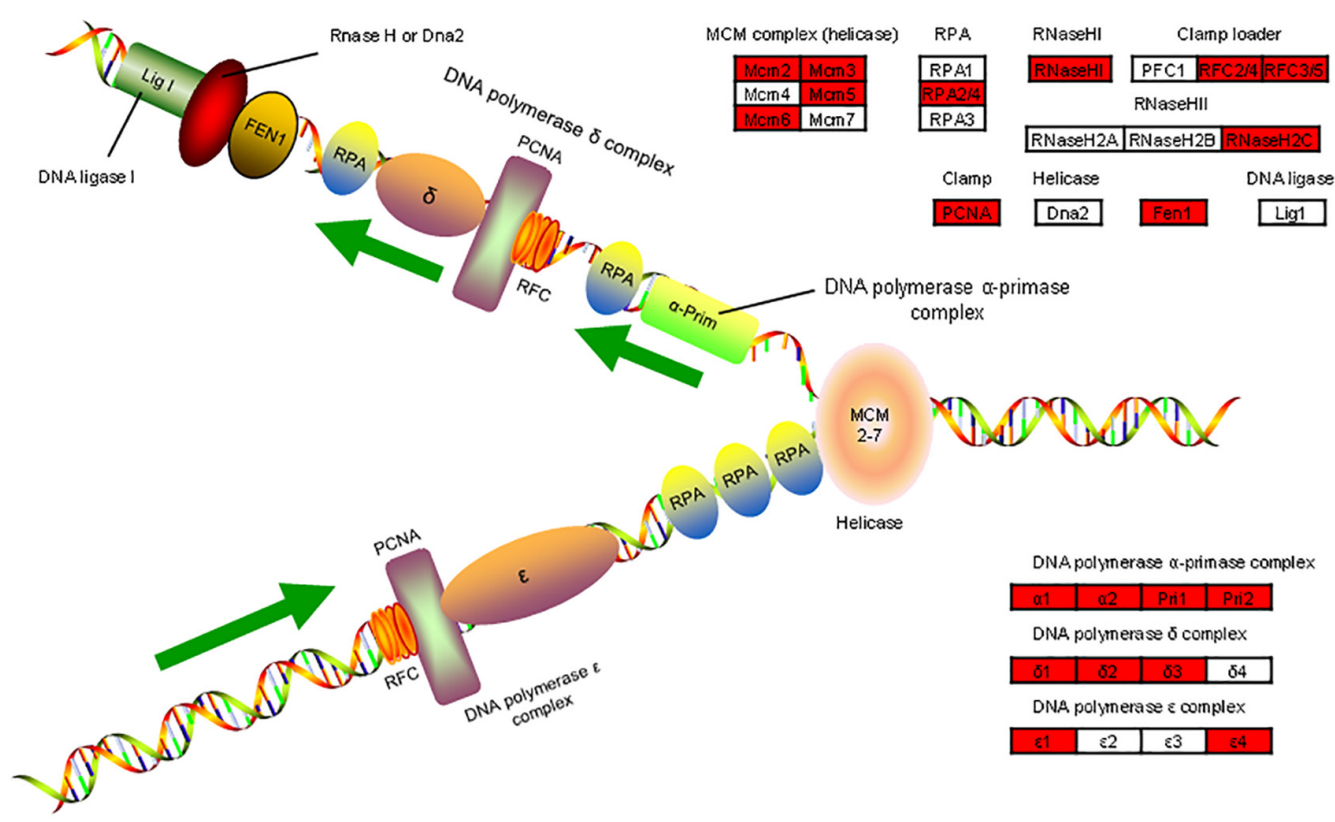

D

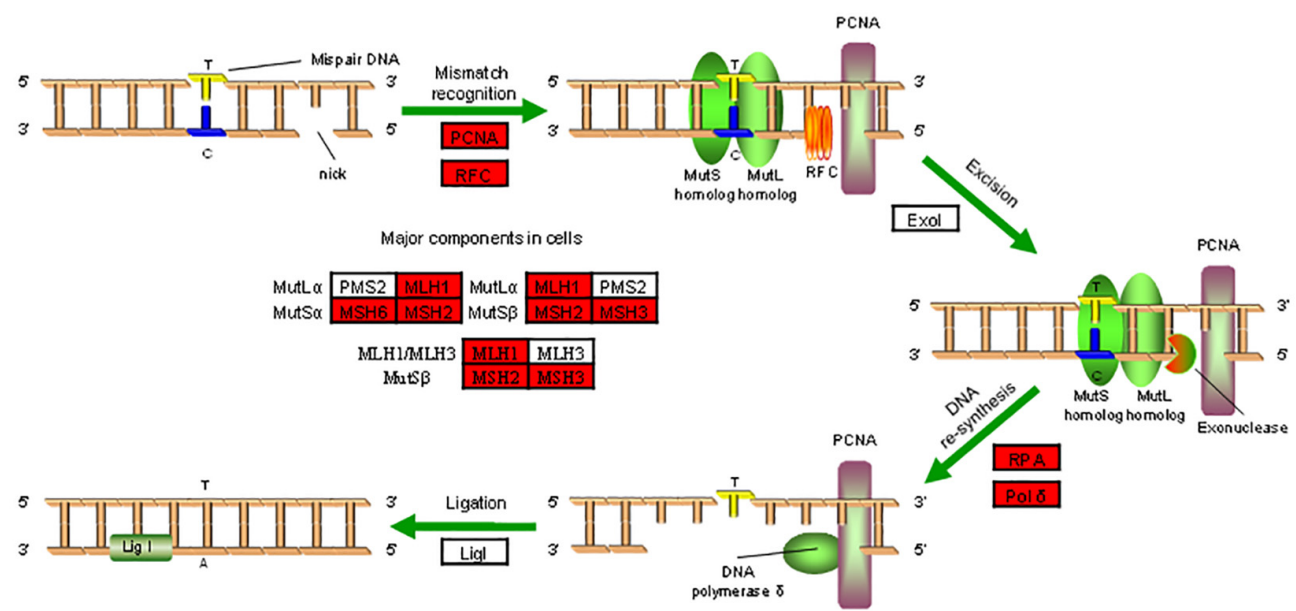

FIGURE 5 | Morphological change in nuclear chromatin caused by phenol and the protection of nuclear DNA. (A) Representative images of cells stained with the DNA specific dye diaminophenylindole (DAPI) are shown in the top column, and images taken by a differential interference contrast (DIC) lens are shown in the bottom column. (B) Percentage of cells containing abnormal chromatin in the presence of each concentration of phenol at 3, 9, and 18 h. Data represent averages of three experiments. At least 100 cells were examined on each bright-field image. (C,D) DNA replication (C) and DNA mismatch repair (D) pathways. Red genes were up-regulated by 2-fold in the presence of $2.0 \mathrm{~g} / \mathrm{L}$ phenol and listed in Supplementary Table S4. 
remained small and compacted (Figure 5A). The percentage of cells with abnormal diffuse nuclear chromatin was recorded in order to investigate the severity of nuclear chromatin damage. As illustrated in Figure 5B, the percentage of cells with nuclear chromatin disorganization remained at a low level (3.86$7.30 \%$ ) when phenol was present or absent, which implied that $0.0-3.0 \mathrm{~g} / \mathrm{L}$ phenol did not cause obvious damage to DNA and chromatin.

The transcriptome data indicated that most of the genes participating in DNA replication and DNA repair showed significant up-regulation in the presence of $2.0 \mathrm{~g} / \mathrm{L}$ phenol (Figures 5C,D and Supplementary Table S4). Genes encoding ribonucleoside-diphosphate reductase subunit M2 (CTRG_01327 and CTRG_01698), as well as genes encoding ribonucleoside-diphosphate reductase subunit M1 (CTRG_01309), were highly expressed in cells exposed to 1.0 and $2.0 \mathrm{~g} / \mathrm{L}$ phenol (Supplementary Table S4). The encoded proteins of the above genes are small and large subunits of ribonucleotide reductase (RNR), which plays a crucial role in $\mathrm{dNTP}$ production and DNA synthesis (Yao et al., 2003). Meanwhile, chromosome transmission fidelity protein 18 (CTRG_00975) was up-regulated by more than 4 -fold in the presence of both 1.0 and $2.0 \mathrm{~g} / \mathrm{L}$ phenol (Mayer et al., 2001; Supplementary Table S4).

\section{Accumulation and Degradation of Unfolded and Misfolded Proteins}

The ER structures of the viable cells were divided into three groups: normal (unfolded), abnormal shapes (folded and fragmented), and necrotic (Figure 6A). When cells were exposed to $0.0,0.5$, and $1.0 \mathrm{~g} / \mathrm{L}$ phenol, normal and abnormal ER structures were distributed roughly 35 and $65 \%$ of cells at $3 \mathrm{~h}$, respectively (Figure $6 \mathrm{C}$ ). Under the same conditions, there was no significant change in the ratio of cells containing normal and abnormal ER structures from 3 to $9 \mathrm{~h}$, but there was a slight increase in the proportion of cells containing abnormal ER at $18 \mathrm{~h}$ (Figure 6C). The necrotic cells and the cells containing abnormal ER accounted for a large share of the observed cells treated with high concentrations of phenol ( 2.0 and $3.0 \mathrm{~g} / \mathrm{L}$ ) at various time points (Figure 6C). These results demonstrated that ER was not significantly injured by phenol at low concentrations $(0.5$ and $1.0 \mathrm{~g} / \mathrm{L})$, but was markedly damaged by phenol at high concentrations (2.0 and $3.0 \mathrm{~g} / \mathrm{L})$. In contrast, the recovery of cell growth in cells exposed to $2.0 \mathrm{~g} / \mathrm{L}$ phenol after $24 \mathrm{~h}$ suggested that certain mechanisms provided enough protein to retain homeostasis in the cells. Previous studies have demonstrated that, after the unfolded protein response (UPR) and autophagy, cells could recover homeostasis and normal ER function (Senft and Ronai, 2015). HSPs functioning as chaperones were implicated in the reversal of amino acid oxidation and refolding of denatured proteins resulting from the UPR (Doong et al., 2003; Obeng et al., 2006; Lanneau et al., 2010). The expression of a gene CTRG_01443, annotated as "small heat shock protein 21" (Hsp21), was up-regulated by 11. 3-, 64-, and 13.9-fold change in the presence of $0.5,1.0$, and $2.0 \mathrm{~g} / \mathrm{L}$ phenol, respectively (Supplementary Table S5). Besides, the gene
CTRG_04372, annotated as co-chaperones in the Hsp70/Hsp90 family, was significantly up-regulated in the presence of $2.0 \mathrm{~g} / \mathrm{L}$ phenol (Supplementary Table S5). Autophagy, as a conserved trafficking pathway, delivered unfolded or misfolded proteins, components, and organelles from the cytoplasm to the vacuole for degradation and recycling (Senft and Ronai, 2015). Four pivotal steps, including the activation of autophagy, the formation of the autophagosome, the cytoplasm-to-vacuole targeting (CVT) pathway, and vacuole fusion, ensured the effective degradation of the contents by vacuole hydrolases (Oku et al., 2006; Suzuki and Ohsumi, 2007; Senft and Ronai, 2015). In the presence of $2.0 \mathrm{~g} / \mathrm{L}$ phenol, it was found that the expression of genes IRE1, ATG11, ATG23, and ATG25, related to the activation of autophagy and the formation of the autophagosome, were up-regulated by more than 2-fold (Supplementary Table S5). However, APE1 and AMS1, which are related to autophagy, showed down-regulation by twofold (Supplementary Table S5).

The vacuole plays a key role in autophagy for the degradation and recycling of unfolded or misfolded proteins (Suzuki and Ohsumi, 2007) and accordingly changes of vacuole morphology in the non-phenol-treated and phenol-treated cells were observed. The observation revealed vacuoles in different configurations that could be classified as follows: a single large vacuole, two to four medium-sized vacuoles, and massively fragmented vacuoles (Figure 6B). After treatment for $3 \mathrm{~h}$, compared with the other treatments, $75 \%$ of cells treated with $0.5 \mathrm{~g} / \mathrm{L}$ phenol contained a single large vacuole. A single large vacuole was also predominant in cells treated with 1.0 and $2.0 \mathrm{~g} / \mathrm{L}$ phenol (71 and 68\%, respectively) (Figure 6D). Similarly processing time, cells treated with non-lethal doses of phenol $(0.5,1.0$, and $2.0 \mathrm{~g} / \mathrm{L})$ exhibited a lower proportion of fragmented vacuoles than untreated cells (Figure 6D). At $9 \mathrm{~h}$ after treatment, cells treated with $1.0 \mathrm{~g} / \mathrm{L}$ phenol (49\%) showed the highest proportion of single large vacuoles, followed by cells treated with $0.5 \mathrm{~g} / \mathrm{L}$ phenol (40\%) (Figure 6D). From these observations, we speculated that low concentrations of phenol suppressed the fragmentation of the cellular vacuole. However, the cells treated with 2.0 and $3.0 \mathrm{~g} / \mathrm{L}$ phenol exhibited a higher proportion of fragmented vacuoles than the untreated cells, after treatment for both 9 and $18 \mathrm{~h}$ (Figure 6D). Since mutation of VAC8 has been correlated with vacuole fragmentation (Oku et al., 2006), the above results might be related to down-regulation of VAC8 (Supplementary Table S5).

\section{Accumulation of Fatty Acid}

The KEGG pathway enrichment analysis revealed downregulation of 13 genes involved in fatty acid degradation (Figure 7). In this pathway, long-chain acyl-CoA synthetase (EC: 6.2.1.3) is responsible for the degradation of hexadecanoate (fatty acid), and the corresponding genes, CTRG_02563 and CTRG_05500, were down-regulated by 11.3- and 7-fold in response to $2.0 \mathrm{~g} / \mathrm{L}$ phenol, respectively (Figure 7). When hexa-decanoyl-CoA was converted into trans-hexadec-2-enoylCoA, the expression of the corresponding genes (CTRG_02374, CTRG_02377, CTRG_02721, and CTRG_05958), annotated as acyl-CoA oxidase (EC: 1.3.3.6) and acyl-CoA dehydrogenase 

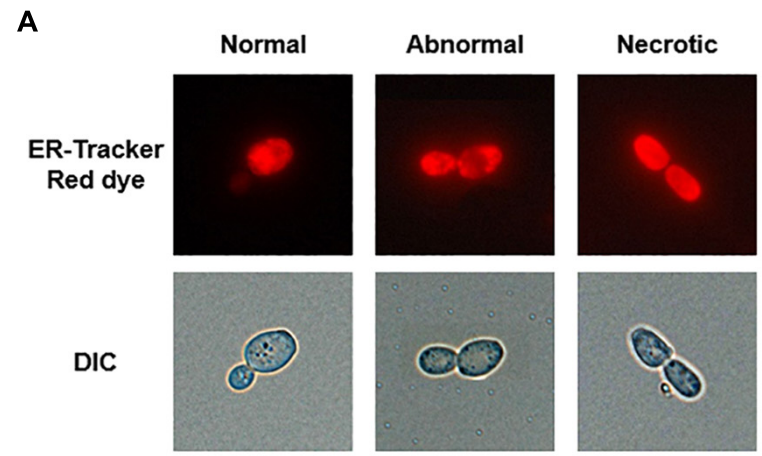

B
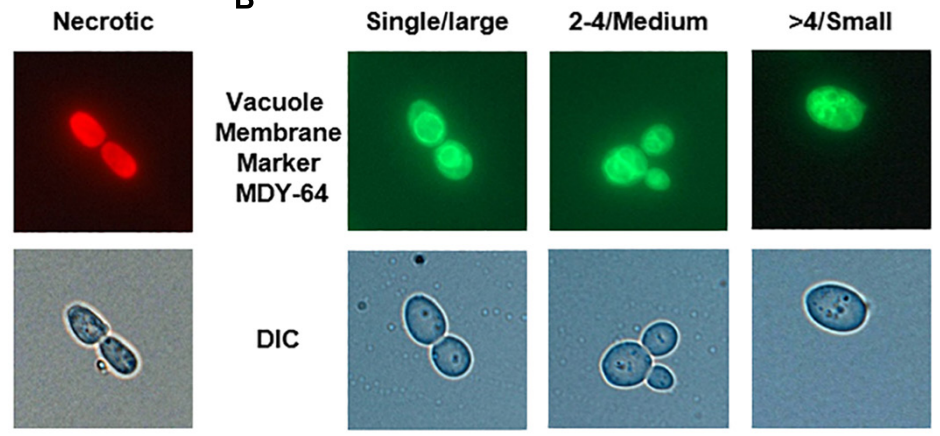

C

Normal $\square$ Abnormal $\square$ Necrotic
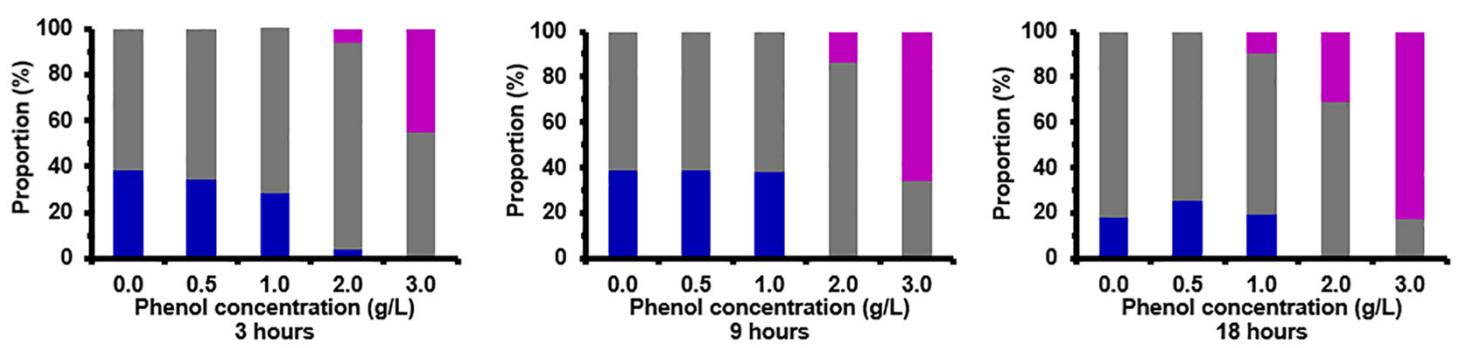

D

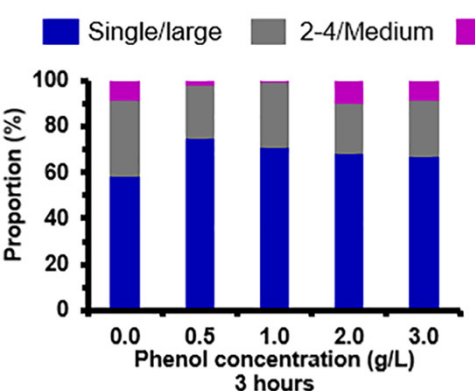

$>4 /$ Small
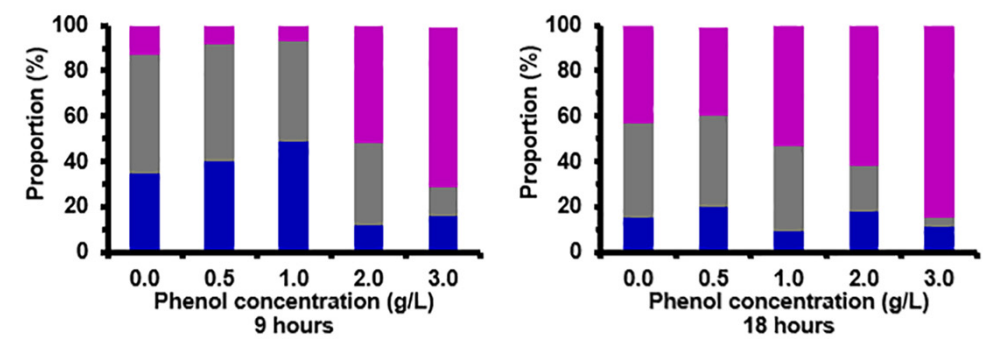

FIGURE 6 | Endoplasmic reticulum (ER) and vacuole damage caused by phenol. Representative images of cells stained with the ER-specific dye ER-Tracker ${ }^{T M}$ Red and vacuole-targeted dye Yeast Vacuole Membrane Marker MDY-64 are shown in the top column, and images taken using a differential interference contrast (DIC) lens are shown in the bottom column. (A) Morphological structure analysis of the ER. (B) Morphological structure analysis of the vacuole. (C) Percentage of cells at each concentration of phenol that displayed normal, abnormal, and necrotic ER at 3, 9, and $18 \mathrm{~h}$. (D) Percentage of cells at each concentration of phenol that contained large, medium, and small vacuoles at 3, 9, and $18 \mathrm{~h}$. Data represent averages of three experiments. At least 100 cells were examined on each bright-field image.

(EC: 1.3.8.7), showed 147-, 12.1-, 2.8-, and 5.7-fold decreases in cells treated with $2.0 \mathrm{~g} / \mathrm{L}$ phenol, respectively (Figure 7). The genes CTRG_01068 and CTRG_02168, which encode acetyl-CoA acyltransferase1 (2.3.1.16), were 7- and 3.7-fold down-regulated in cells treated with $2.0 \mathrm{~g} / \mathrm{L}$ phenol (Figure 7). In addition, the differential expression analysis implicated genes encoding aldehyde dehydrogenase (1.2.1.3) and alcohol dehydrogenase (1.1.1.1) in the conversion of fatty acid to alcohol (Figure 7). Specifically, CTRG_05836, CTRG_00882, CTRG_05482, CTRG_01329, and CTRG_05010 were significantly downregulated in response to $2.0 \mathrm{~g} / \mathrm{L}$ phenol exposure (Figure 7). These results suggested that decreased fatty acid degradation efficiency, caused by the down-regulation of expression of related genes, could elevate the intracellular fatty acid content or change the fatty acid component in cells (Kurosawa et al., 2015; Zhou et al., 2017).

\section{Cell-Wall Remodeling}

Previous studies have found that cell-wall remodeling can lead to increased ethanol resistance in yeast (Teixeira et al., 2014). Our comparative transcriptome analysis revealed $>2$-fold upregulation of six genes related to cell-wall biogenesis and integrity in response to 1.0 and $2.0 \mathrm{~g} / \mathrm{L}$ phenol, including CTRG_05721, CTRG_05949, CTRG_00608, CTRG_00036, CTRG_01855, and CTRG_03473 (Supplementary Table S6). Genes involved in cell-wall biogenesis may contribute to the increased resistance of C. tropicalis SHC-03 to phenol. A series of differential expression analyses of genes up-regulated in response to $2.0 \mathrm{~g} / \mathrm{L}$ 


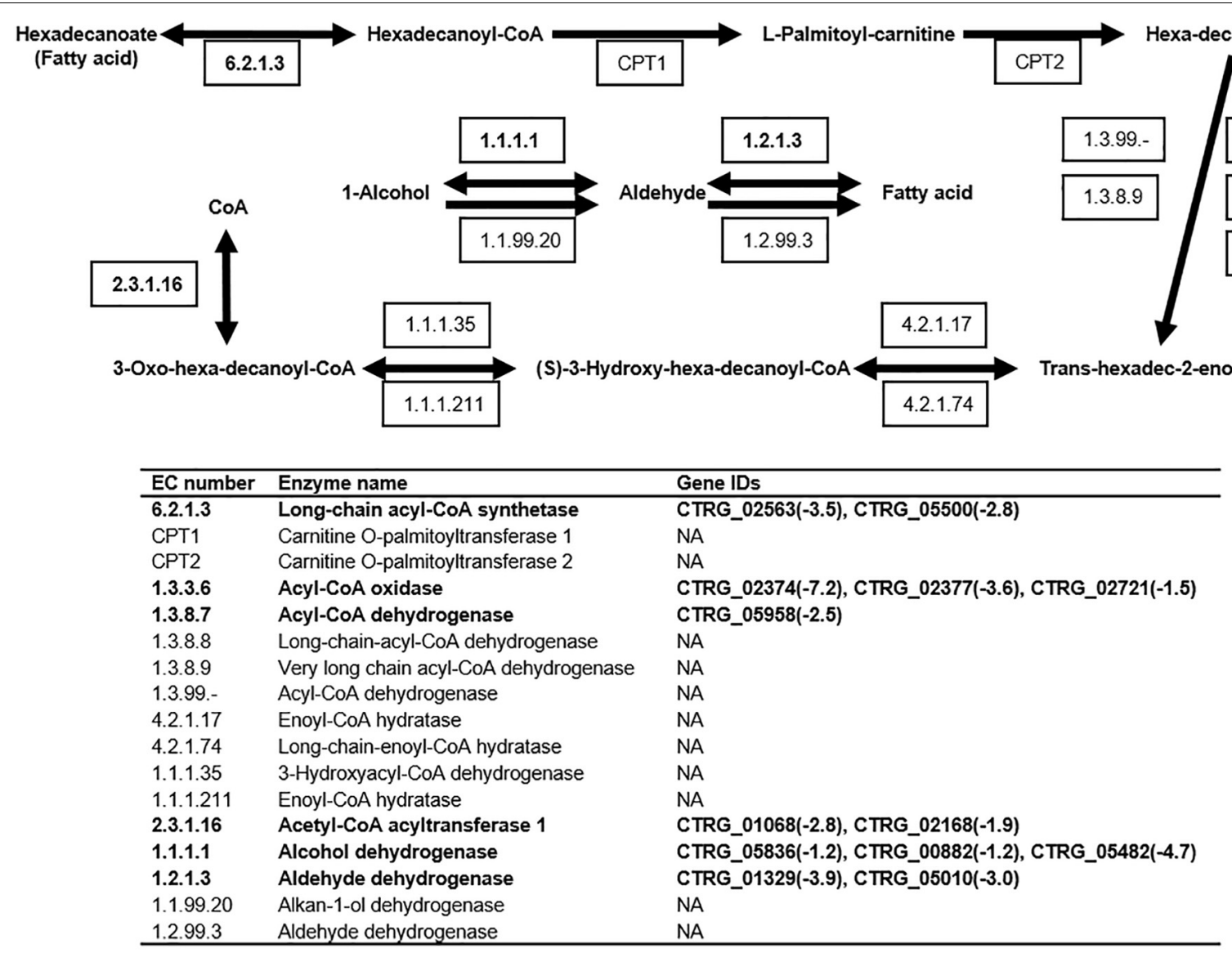

FIGURE 7 | Fatty acid degradation pathway in C. tropicalis SHC-03. Known enzymatic reactions in C. tropicalis are shown in bold font. Expression levels of genes with values of $\log _{2}$ (fold change) in response to $2.0 \mathrm{~g} / \mathrm{L}$ phenol, compared with the control group, are shown. NA, none annotated.

phenol revealed enrichment in the chitin synthesis pathway (Figure 8A and Supplementary Table S6). As illustrated in Figure 8A, during the conversion of glucose to chitin, the expression levels of CTRG_00414, CTRG_00601, CTRG_01436, CTRG_03651, CTRG_03585, CTRG_05721, and CTRG_05949 were markedly increased. In addition, most of the genes in the chitin degradation pathway (chitin to chitobiose or N-AcetylD-glucosamine), including CTRG_05456 and CTRG_05827 (encoding chitinase) and CTRG_01063 (encoding beta-Nacetylhexosaminidase), were significantly down-regulated in expression (Figure 8A and Supplementary Table S6). In the process of converting chitin to chitosan, CTRG_01049, which encodes chitin deacetylase, was dramatically up-regulated; by 26.5-fold (Figure 8A and Supplementary Table S6). The upand down-regulated expression of these genes probably served to increase the accumulation of chitin and chitosan in the cell wall. To confirm the increased phenol tolerance of cells that had undergone cell wall remodeling, we conducted cellwall susceptibility analyses of the phenol-treated and nonphenol-treated cells using lytic enzyme, a $\beta$-1,3-glucanase from Arthrobacter luteus (Teixeira et al., 2014). After $3 \mathrm{~h}$, the cell density $\left(\mathrm{OD}_{600}\right)$ of samples treated with 0.0 and $0.5 \mathrm{~g} / \mathrm{L}$ phenol decreased significantly upon addition of lyticase to the medium.
This decrease was even more pronounced in cells treated with 1.0 and $3.0 \mathrm{~g} / \mathrm{L}$ phenol, decreasing to less than $10 \%$ of the initial cell density at $4 \mathrm{~h}$ (Figure $\mathbf{8 B}$ ). The cell density of samples treated with $2.0 \mathrm{~g} / \mathrm{L}$ phenol dropped slowly after lyticase was added into the medium for $4 \mathrm{~h}$, decreasing to about $65 \%$ at $4 \mathrm{~h}$ (Figure 8B). After treatment with phenol for $9 \mathrm{~h}$, the samples in 0.0 and $0.5 \mathrm{~g} / \mathrm{L}$ phenol still displayed the most rapid cell-density decline in the lyticase-supplemented medium; the decrease in cell density in these samples was greater than the cell-density decrease seen in the samples in 1.0-3.0 g/L phenol (Figure 8C). However, the cell density of the sample in $3.0 \mathrm{~g} / \mathrm{L}$ phenol dropped more quickly than all of the others, at $3 \mathrm{~h}$ (Figure $\mathbf{8 C}$ ). The resistance of cells to lyticase after treatment with 1.0 and $2.0 \mathrm{~g} / \mathrm{L}$ phenol for $9 \mathrm{~h}$ was similar to that of cells treated with the corresponding concentration of phenol for $3 \mathrm{~h}$ (Figure $8 \mathrm{C}$ ). In cells exposed to phenol for $18 \mathrm{~h}$, the cell density of the sample treated with $3.0 \mathrm{~g} / \mathrm{L}$ phenol descended sharply, decreasing to about $12 \%$ after addition of lyticase to the medium and incubation for $4 \mathrm{~h}$ (Figure 8D). The cell density of samples treated with 1.0 and $2.0 \mathrm{~g} / \mathrm{L}$ phenol for $18 \mathrm{~h}$ dropped slowly after the $4 \mathrm{~h}$ lyticase treatment. In contrast, the cell density in the samples with 0.0 and $0.5 \mathrm{~g} / \mathrm{L}$ phenol showed no significant decline (Figure $\mathbf{8 D}$ ). The results demonstrated that treatment for 3 and $9 \mathrm{~h}$ with $1.0-3.0 \mathrm{~g} / \mathrm{L}$ phenol caused 


\section{A}

$\begin{array}{lllllll}6 & 4 & 2 & 0 & -2 & -4 & -6\end{array}$

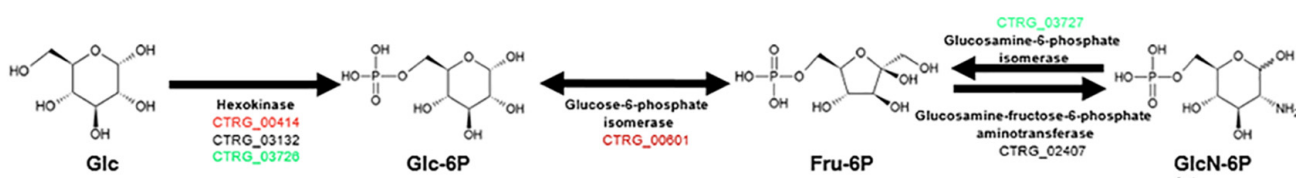
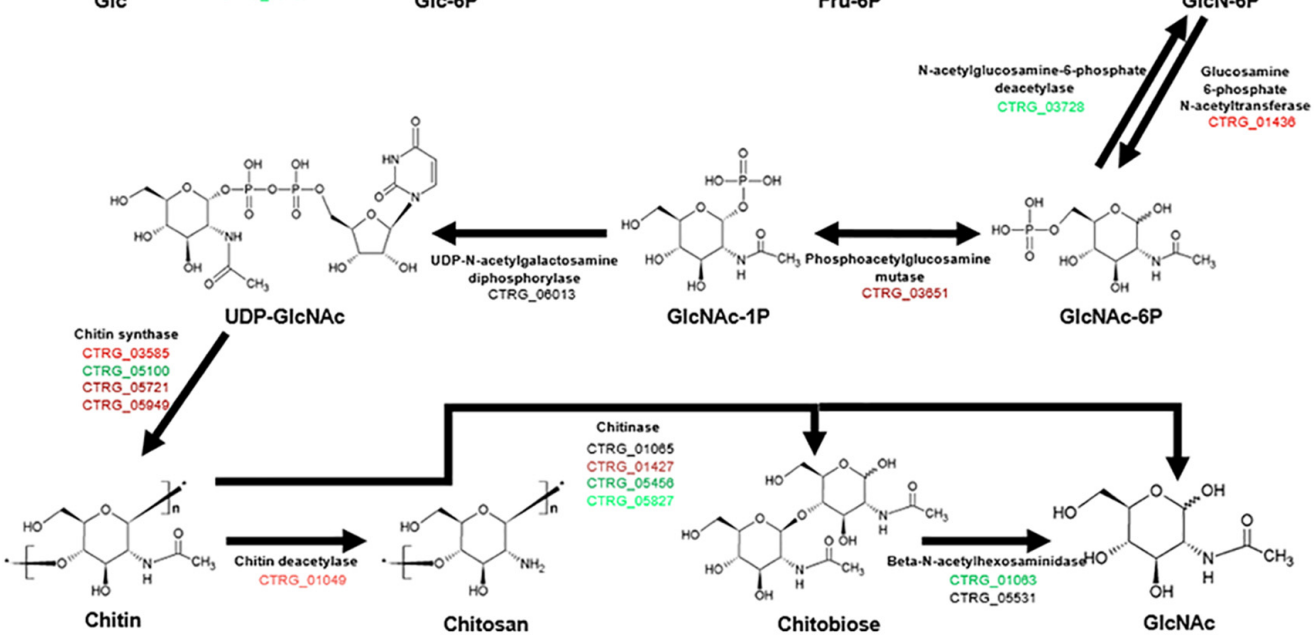

GICNAC-1P

GICNAc-6P

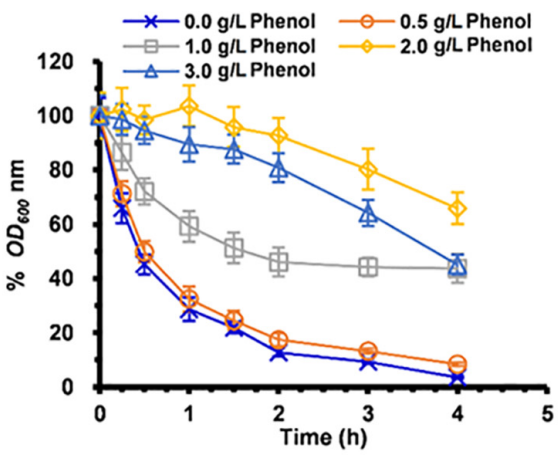

D

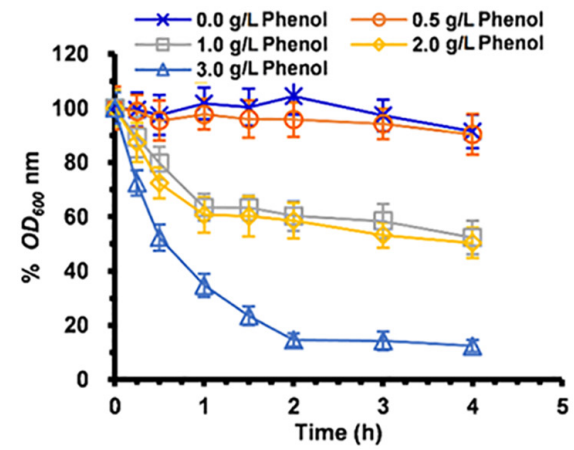

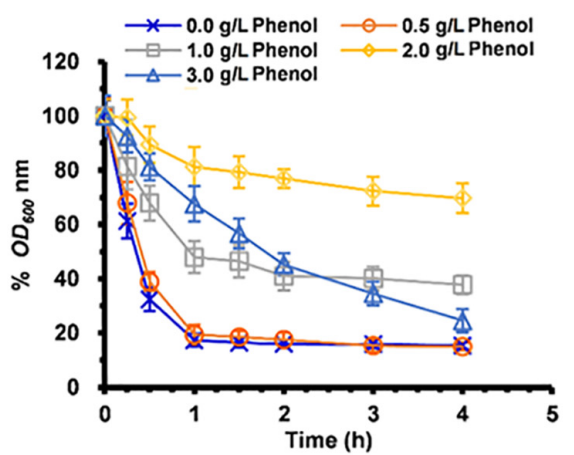

FIGURE 8 | Synthesis and degradation of chitin in cells exposed to $2.0 \mathrm{~g} / \mathrm{L}$ phenol and susceptibility to lyticase of cells treated with $0.0-3.0 \mathrm{~g} / \mathrm{L}$ phenol for 3,9 , and 18 h. (A) Pathway showing genes involved in chitin synthesis and degradation. The color codes red, black, and green represent up-regulated, normal, and down-regulated expression, respectively, in the presence of $2.0 \mathrm{~g} / \mathrm{L}$ phenol. Glc, D-Glucose; Glc-6P, D-Glucose-6-phosphate; Fru-6P, D-Fructose-6-phosphate; GlcN-6P, D-Glucosamine-6-phosphate; GlcNAc-6P, N-Acetyl-D-glucosamine 6-phosphate; GlcNAc-1P, N-Acetyl-alpha-D-glucosamine 1-phosphate; UDP-GlcNAc, UDP-N-acetyl-alpha-D-glucosamine; GlcNAc, N-Acetyl-D-glucosamine. The expression levels of the genes $\left(\log _{2}\right.$ transformed) are listed in

Supplementary Table S6. The mean values of relative optical density are presented with vertical error bars, each representing a single standard deviation $(n=3)$. (B-D) Change in cell density after treatment in PBS containing lyticase from 0 to $4 \mathrm{~h}$ after incubation. Cells treated for (B) $3 \mathrm{~h}$, (C) $9 \mathrm{~h}$, and (D) $18 \mathrm{~h}$ under phenol stress or no phenol stress. The mean values of relative optical density are presented with vertical error bars, each representing a single standard deviation $(n=3)$. 
increased resistance of cells to lyticase, with a maximal effect seen at $2.0 \mathrm{~g} / \mathrm{L}$ phenol. While $2.0 \mathrm{~g} / \mathrm{L}$ phenol appeared to be the optimal concentration for lyticase resistance, cells treated with 0.0 and $0.5 \mathrm{~g} / \mathrm{L}$ phenol also exhibited significantly increased resistance to lyticase after $18 \mathrm{~h}$ and cells treated with $3.0 \mathrm{~g} / \mathrm{L}$ phenol for $18 \mathrm{~h}$ showed decreased resistance to lyticase compared with this treatment after 3 and $9 \mathrm{~h}$.

\section{MDR/MXR Transport}

One effective detoxification mechanism is the active efflux mechanism, which has been shown to reduce the level of intracellular toxic compounds, resulting in retention of the physiological activities of the cells (Dos Santos et al., 2014). The major facilitator superfamily (MFS) and ATP-binding cassette $(\mathrm{ABC})$ subfamily are the two most important groups of multidrug/multixenobiotic resistance (MDR/MXR) transporters responsible for the efflux of toxic compounds (Sa-Correia et al., 2009). In response to at least two concentrations of phenol, the MFS genes CTRG_03938, CTRG_00385, and CTRG_03729 showed a $>2$-fold increase in expression (Supplementary Table S7). Specifically, CTRG_00385 was up-regulated by 7-, 18-, and 169-fold in response to $0.5,1.0$, and $2.0 \mathrm{~g} / \mathrm{L}$ phenol. Additionally, a statistical analysis of differential gene expression showed that 14 genes belonging to the MFS and ATPbinding cassette (ABC) subfamily exhibited greatly up-regulated expression in the presence of phenol (Supplementary Table S7). As illustrated in Supplementary Table S7, 2, 6, and 10 transporter genes were significantly up-regulated in response to $0.5,1.0$, and $2.0 \mathrm{~g} / \mathrm{L}$ phenol, which indicated that the number of up-regulated transporter genes increased with the rise in phenol concentration.

\section{Transcriptional Responses for Phenol Degradation}

Previous studies have illustrated that phenol degradation is the vital detoxification mechanism of C. tropicalis in response to phenol (Jiang et al., 2005; Varma and Gaikwad, 2009).
Considering the molecular mechanism, the biodegradation of phenol mainly relies on subsequent enzymatic steps via the $\beta$-ketoadipate pathway in C. tropicalis (Krug et al., 1985). The crucial enzyme in this pathway, phenol 2-monooxygenase (EC 1.14.13.7), is responsible for the hydroxylation of phenol to catechol, which is a rate-limiting step (Krug et al., 1985; Figure 9). To date, two genes encoding phenol 2-monooxygenase, CTRG_00423 and CTRG_03102, have been discovered in C. tropicalis strains JH8 and MYA-3404, respectively (Butler et al., 2009; Long et al., 2014). In the present study, the comparative transcriptomics data did not indicate that CTRG_00423 and CTRG_03102 were significantly up-regulated under phenol stress after treatment for $3 \mathrm{~h}$ (Figure 9). In the second step of the $\beta$-ketoadipate pathway, catechol 1,2-dioxygenase (EC 1.13.11.1) is responsible for the conversion of catechol to cis,cis-muconate (Figure 9). CTRG_01732 and CTRG_00171, encoding catechol 1,2-dioxygenase, were not significantly up-regulated in response to different concentrations of phenol (Figure 9). The above results suggest that the phenol degradation mechanism of C. tropicalis SHC-03 was probably not activated.

\section{DISCUSSION}

In this study, the cells recovered and returned to normal growth $20 \mathrm{~h}$ after the treatment (Figure 1A), which indicated that detoxification and/or tolerance mechanisms should be activated to protect the cells from the toxicity of phenol and retain the viability of cells throughout the stress period. The determination of phenol concentration in each sample showed that the degradation of phenol in C. tropicalis was not activated (Figure 1B). Meanwhile, the transcriptome analysis of key genes (CTRG_00423, CTRG_03102, CTRG_01732, and CTRG_00171) related to phenol degradation demonstrated that phenol did not stimulate the phenol degradation mechanism of C. tropicalis in YPD medium (Figure 9). Therefore, we considered that the tolerance mechanism of $C$. tropicalis to phenol plays a critical role in maintaining the viability of phenol-treated cells.

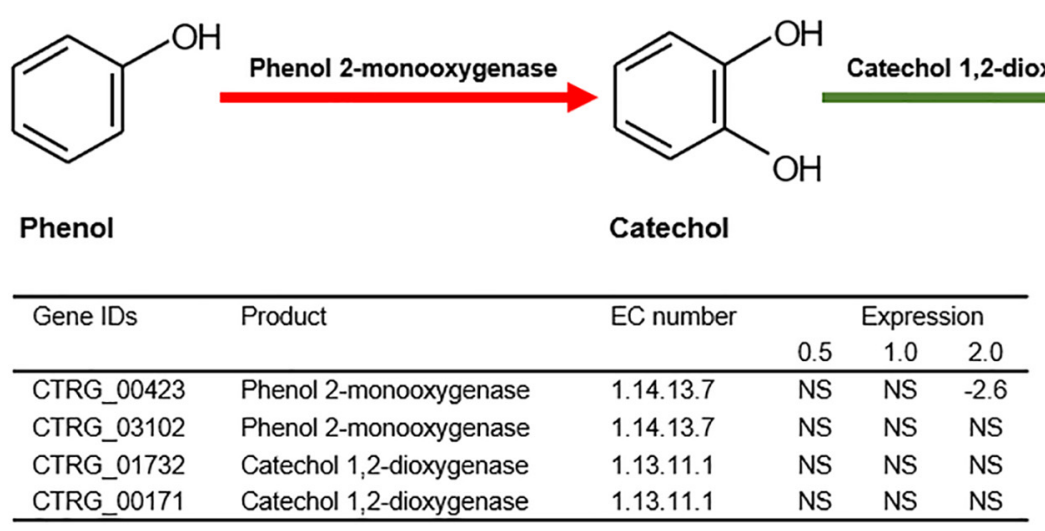

FIGURE 9 | The first and second step of the $\beta$-ketoadipate pathway in the biodegradation of phenol. Expression levels of genes involved in the first and second step of the $\beta$-ketoadipate pathway are represented by the values of $\log _{2}$ (fold change) in response to different concentrations of phenol, compared with the control group. NA, not significant. 
In the present study, the treated cells exhibited serious damage to the mitochondrial membrane and high-level accumulation of ROS after the treatment for $3 \mathrm{~h}$, which can cause damage to DNA, proteins, lipids, and the cytoskeleton (Figure 3; Gourlay and Ayscough, 2005; Perrone et al., 2008; Rowe et al., 2008), and then seriously affect the physiological and biochemical functions of cells. Interestingly, the percentages of the cells accumulating ROS declined to a lower level at $9 \mathrm{~h}$ (Figure 3D). Since efficient enzymatic and non-enzymatic antioxidant defense systems were found to be responsible for the scavenging of excessive ROS and protection of cells from oxidative damage (Hossain et al., 2006), we speculated that the associated genes, such as SOD, GPX, CTT, GLR, might be activated. The results from RNA-seq showed that these genes were not up-regulated in response to $3 \mathrm{~h}$ exposure to several concentrations of phenol (Supplementary Table S3), which implied that these antioxidant defense systems were not activated at the transcriptional level in response to phenol. To clarify the mechanism related to the scavenging of the intracellular ROS between 3 and $9 \mathrm{~h}$, the activity assays of SOD, GPX, CTT, and GLR, as well as determination of GSH content, were conducted (Figure 4). As illustrated in Figure 4, the activities of SOD, GPX, and GLR showed obvious changes correlating with different conditions (phenol concentration and processing time). These changes were distinct from those at the transcriptional level. We hypothesized that differing regulation at the translational level might lead to the above inconsistent findings.

The results from the SOD activity assays showed that the SOD activities in different treatments remained high at 3 and $6 \mathrm{~h}$, but were very low at $9 \mathrm{~h}$, which implies that most of the $\mathrm{O}_{2}{ }^{-}$ probably had been converted to $\mathrm{H}_{2} \mathrm{O}_{2}$, and the SOD activity was sufficient to retain homeostasis of intracellular ROS at a low level after the treatment for $9 \mathrm{~h}$ (Figure 4A). During the conversion of $\mathrm{H}_{2} \mathrm{O}_{2}$ to $\mathrm{H}_{2} \mathrm{O}$, GPX activities in the treatments with 1.0 and $2.0 \mathrm{~g} / \mathrm{L}$ phenol exhibited a dramatic increase, but CTT activity was not detected in any of the treatments, implying that GPX played an important role in the reduction of $\mathrm{H}_{2} \mathrm{O}_{2}$ after the treatment for 6 and $9 \mathrm{~h}$. Additionally, the high activity of GLR guarantees sufficient supplementation of GSH activity to contribute to the reduction of $\mathrm{H}_{2} \mathrm{O}_{2}$ catalyzed by GPX at 6 and $9 \mathrm{~h}$ (Figure 4D). In summary, the up-regulation of intracellular SOD activity (involved in the dismutation of $\mathrm{O}_{2}{ }^{-}$) at 3 and $6 \mathrm{~h}$, and the up-regulation of intracellular GPX activity (involved in the reduction of $\mathrm{H}_{2} \mathrm{O}_{2}$ ) at 6 and $9 \mathrm{~h}$, promoted the detoxification of endogenous ROS induced by phenol and low-level intracellular ROS.

The morphological structure analysis of nuclei demonstrated that phenol did not induce significant chromatin damage when the concentration of phenol was climbing (Figures 5A,B and Supplementary Table S4). Since chromatin protection mechanisms are associated with the DNA damage response (Masutomi et al., 2005), we speculated that ROS did not cause serious DNA damage. The transcriptome data showed that up-regulated expression of these genes, responsible for DNA repair, DNA synthesis, dNTP production, and chromatin protection, probably played a key role in protecting DNA, dNTPs, and chromatin from damage by ROS, and contributed to the maintenance of the viability of cells and the increased tolerance of $C$. tropicalis SHC-03 to phenol. Additionally, phenolic compounds (luteolin and quercetin) as antioxidants have been found to significantly decrease DNA damage (Lima et al., 2006). Perhaps phenol can function in a similar manner to luteolin or quercetin, helping cells to retain DNA and chromatin homeostasis.

Phenol-induced redox imbalance and ROS-induced protein damage can also cause unfolded or misfolded proteins to accumulate in the ER lumen and thereby induce ER stress (ERS) (Perrone et al., 2008; Senft and Ronai, 2015). The high concentration of phenol $(2.0 \mathrm{~g} / \mathrm{L})$ caused serious damage to the ER at 3-18 h after treatment (Figure $6 \mathrm{C}$ ), but the cell growth recovered in the presence of $2.0 \mathrm{~g} / \mathrm{L}$ phenol. These results suggested that several pathways were triggered by ERS to guarantee the refolding of unfolded protein, the degradation of misfolded proteins, the restoration of normal ER function, and the maintenance of cell survival (Senft and Ronai, 2015). Two key fundamental pathways have been associated with response to ERS: one based on chaperone proteins and the other based on autophagy (Senft and Ronai, 2015). Previous studies have shown that HSPs can act as molecular chaperones associated with the folding, trafficking, protection, and renaturation of cellular proteins that have undergone the heat shock response (Walter and Buchner, 2002). Additionally, the up-regulation of the genes in the Hsp70/Hsp90 family is implicated in the adaptation and resistance of $C$. albicans to stress (Demand et al., 2001; Doong et al., 2003). In the present study, the genes, annotated as Hsp21and the co-chaperone of the Hsp70/Hsp90 family, were up-regulated by more than 2 -fold in the presence of phenol (Supplementary Table S5). Hence, the accumulation of these HSPs might serves to protect the cellular proteins and facilitate the degradation of misfolded proteins via the ubiquitin proteasome system and relieve ERS, thereby improving phenol resistance in C. tropicalis SHC-03. Additionally, UPR can activate 27 autophagy-related genes (ATGs) which control autophagy in S. cerevisiae (Suzuki and Ohsumi, 2007). In the present study, the transcriptome data showed that the ATGs, except for ATG11, ATG23, and ATG25, were no marked changes in the expression level. In addition, expression of the hydrolase genes APE1 and AMS1, the encoded proteins of which are specifically transported by autophagy and the CVT pathway (a type of selective autophagy) to the vacuole for hydrolyzation of proteins (Wang and Klionsky, 2003), was down-regulated at $3 \mathrm{~h}$ after the phenol treatment. We also surveyed the expression of genes belonging to the PERK-eIF2 $\alpha$ pathway, ATF6, IRE1, ATF4, and CHOP, which have been associated with the induction and regulation of autophagy and chaperones (Senft and Ronai, 2015). Only IRE1 (CTRG_04146) showed a change in expression, and its expression was up-regulated by more than 2 -fold in the presence of $2.0 \mathrm{~g} / \mathrm{L}$ phenol at $3 \mathrm{~h}$. In summary, compared with autophagy, HSP-mediated proteasomal degradation played the more dominant role in the relief of ERS triggered by phenol at the early stage of treatment.

As a compartmentalized organelle, the vacuole contains a series of hydrolases which can degrade damaged or unfolded 


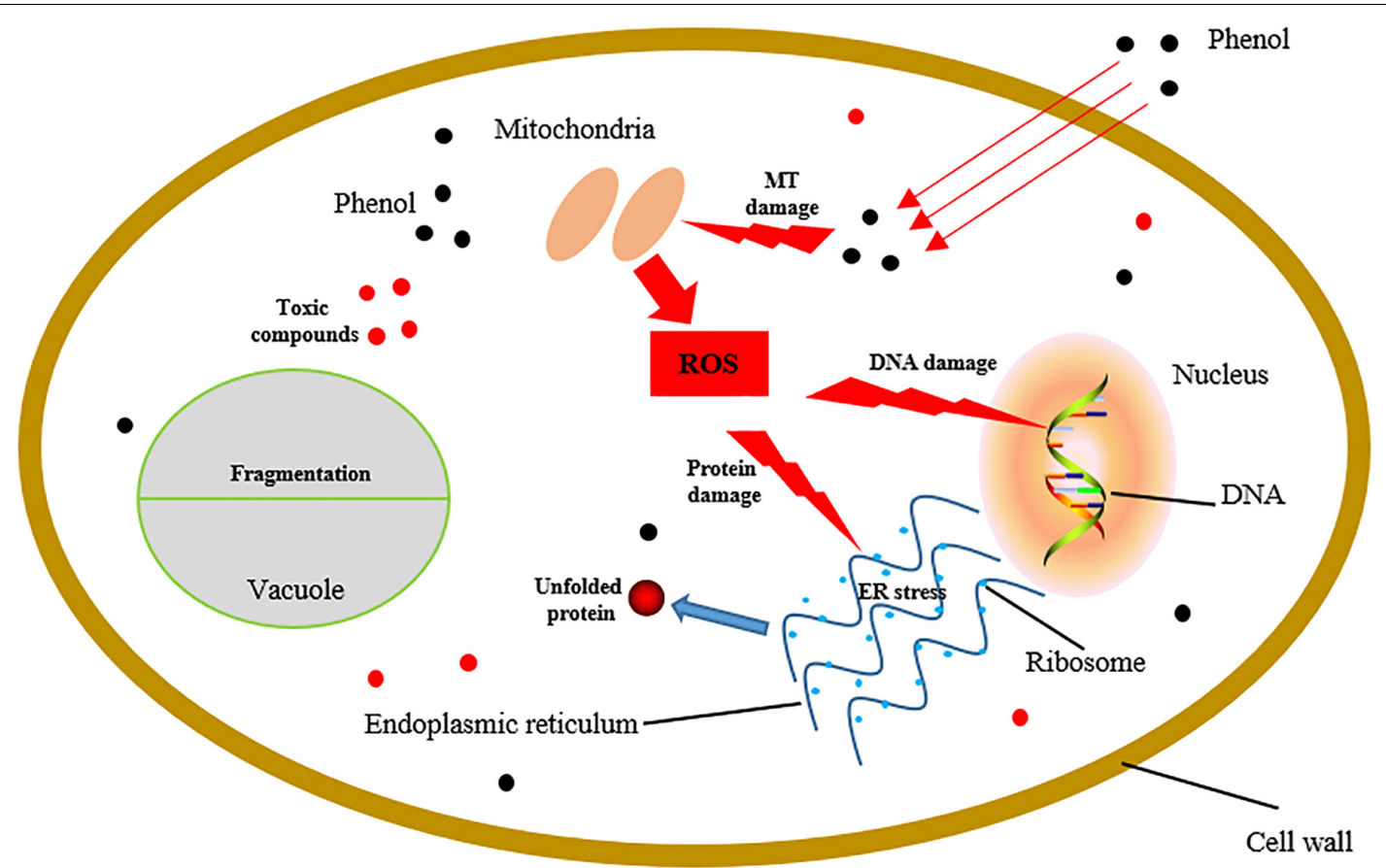

Adaptive response

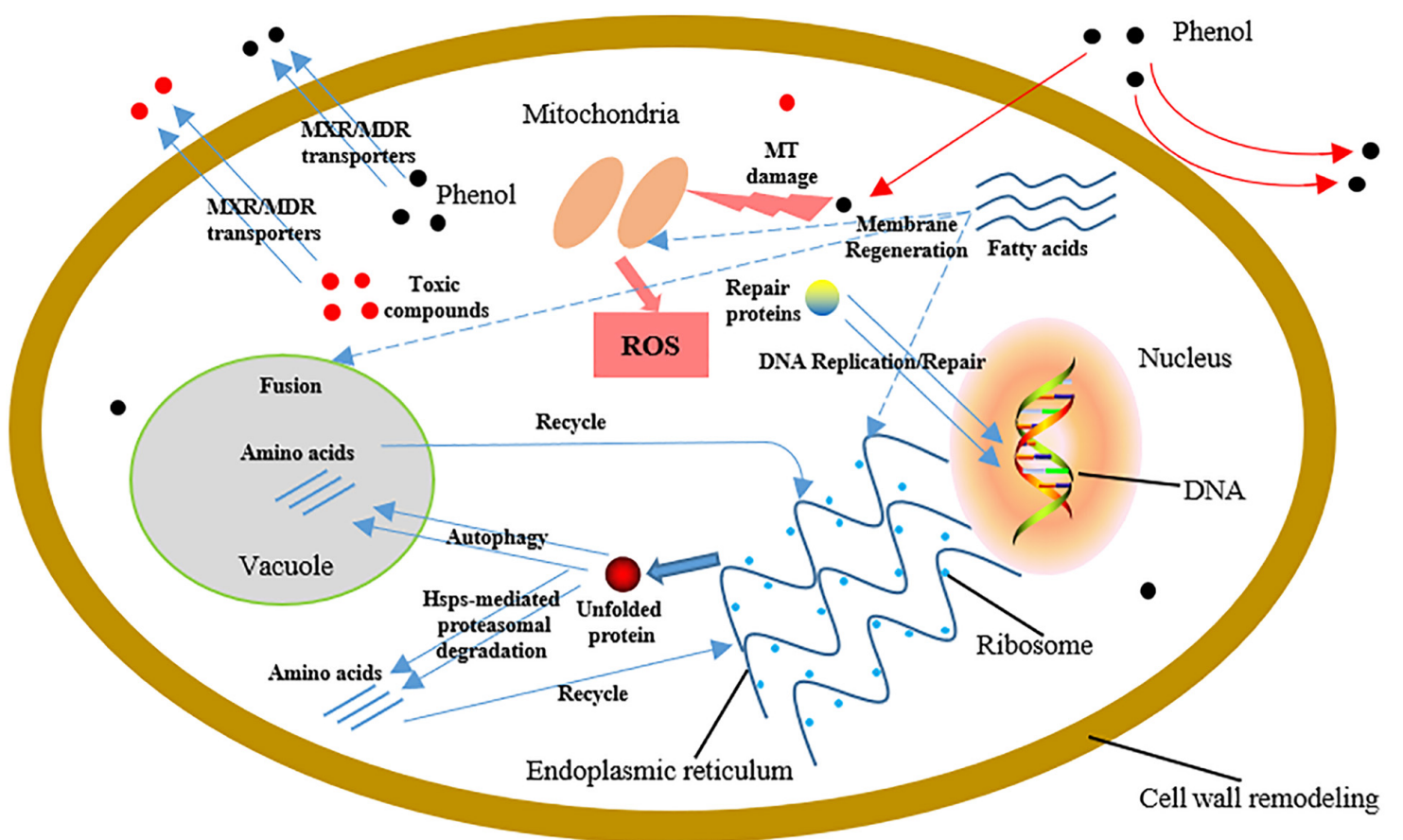

FIGURE 10 | Schematic diagram showing cellular damage to C. tropicalis SHC-03 caused by phenol, and tolerance mechanisms to phenol at the early stage of treatment. MT, mitochondria.

proteins from the cytoplasm in S. cerevisiae during autophagy (Wang and Klionsky, 2003). It has been found that increased vacuolar volume (or the fusion of a fragmented vacuole) can sufficiently improve the hydrolytic capacity for autophagy (Baba et al., 1994). Our morphological observation demonstrated that low concentrations of phenol might block the fragmentation of 
the cellular vacuole in order to allow the cell to retain efficient autophagy (Figure 6D). Unfortunately, the results from RNA-seq demonstrated that the expression of the genes TORC1, SIT4, and VPS1, which regulate the fragmentation or fusion of the vacuole, did not significantly change under phenol stress at $3 \mathrm{~h}$ (data not shown). Perhaps several unknown genes involved in vacuole fusion were responsible for the higher proportion of cells containing large vacuoles. Therefore, a follow-up study will be conducted to characterize these genes. However, we did find that the proportion of cells containing large vacuoles was lower in the cells treated with $2.0 \mathrm{~g} / \mathrm{L}$ phenol than in the untreated cells, at 9 and $18 \mathrm{~h}$ (Figure 5D). As the knockout of VAC8 (CTRG_04061) has been shown to cause fragmentation of vacuoles (Oku et al., 2006), our results can probably be attributed to significant down-regulation of VAC8 (Supplementary Table S5). Since the increased synthesis of fatty acid could promote the formation of lipid membranes and increase the tolerance of S. cerevisiae and Chlorella strains to phenol (Schneiter et al., 2000; Yang et al., 2012; Zhou et al., 2017), the accumulation of fatty acid in this study was likely related to the increased tolerance of $C$. tropicalis to high concentrations of phenol. Interestingly, the accumulation of fatty acids was found to be associated with the fragmentation of the vacuole (Schneiter et al., 2000). This might explain how the proportion of cells containing fragmented vacuoles when exposed to under $2.0 \mathrm{~g} / \mathrm{L}$ phenol stress was higher than that in the untreated samples at 9 and $18 \mathrm{~h}$ (Figure 6).

Since chitin is a structural microfibrillar component and is associated with cell wall rigidity (Bulik et al., 2003; RuizHerrera et al., 2002), accumulation of chitin in cell walls in this study might lead to cell wall remodeling and then promotes the adaptation of cells to hypo-osmotic conditions, increases the resistance of cells to stress, reduces the production of intracellular ROS, and prevents the entrance of phenol into the cells (Aguilar-Uscanga and Francois, 2003; Deshpande et al., 1997). Additionally, the cell wall susceptibility analysis demonstrated that phenol certainly induced the increased resistance of cells to stress. However, it remains to be studied whether it was the accumulation of chitin induced by phenol, and related to cell wall remodeling, that improved the phenol resistance of C. tropicalis.

The active efflux mechanism can enable the cell to retain the intracellular drug/xenobiotic concentration at low levels and maintain the viability of cells under stress from these toxic compounds (Sa-Correia et al., 2009; Ma and Liu, 2010). In our study, at different concentrations of phenol, 14 genes encoding MDR/MXR transporters, especially CTRG_00385, showed significantly up-regulated expression (Supplementary Table S7). Additionally, as the phenol concentration increased, the up-regulated transporter genes became more numerous. Based on these results, we reasoned that there were definite connections between an active efflux mechanism and the tolerance and response of C. tropicalis to phenol. In S. cerevisiae, QDR1 (YIL120W), a multidrug transporter from the MFS, modulates the assembly of the outer spore wall and is responsible for resistance to quinidine, ketoconazole, and fluconazole (Nunes et al., 2001; Lin et al., 2013). Additionally, as illustrated in
Figure 8A, CTRG_01049, which encodes chitin deacetylase, an enzyme that catalyzes the conversion of chitin to chitosan, was up-regulated by 26.5 -fold. Since the spore wall is primarily composed of chitosan (Baker et al., 2007; Neiman, 2011), upregulated expression of CTRG_01049 should lead to excess accumulation of chitosan in the spore wall. Since mature spores, as quiescent cells, exhibit resistance to organic solvents, heat, and digestive enzymes, and since chitosan and dityrosine layers of the spore wall prominently contribute to stress resistance, a hypothesis has been proposed that sporulation of C. tropicalis is activated in order to reduce the assault of phenol to cells (Pammer et al., 1992; Kupiec et al., 1997). However, according to eosin Y staining method (Lin et al., 2013), we observed no spores in the samples at 3, 9, and $18 \mathrm{~h}$ after cells were exposed to different concentrations of phenol (data not shown). This suggests the possible need for further exploration of the mechanisms underlying sporulation in C. tropicalis.

\section{CONCLUSION}

C. tropicalis SHC-03 cells are treated with different concentrations of phenol as a representative of pollutants in environment for investigating the tolerance mechanisms of C. tropicalis to phenol. The experimental results indicated that phenol can result in massive accumulation of ROS. Although these intracellular ROS were found to be scavenged by SOD and GPX, the accumulation of ROS in the early stage after phenol treatment could cause damage to DNA, proteins, and lipids (Figure 10), and this stress could lead to morphological changes in the structure of the endoplasmic reticulum and vacuole. To reduce this damage, a series of protection mechanisms were activated. The DNA repair and synthesis system serve to ensure the stability of heredity, and key enzymes retain the fidelity of chromosome transmission and the stability of chromosomal structure. HSP-mediated proteasomal degradation and autophagy served to maintain intracellular protein homeostasis and accelerated recycling of proteins. Additionally, the accumulation of fatty acids contributed to the regeneration and repair of organelles with membrane systems. Cell wall remodeling minimized both import of phenol into the cells and production of intracellular ROS. The MXR/MDR transporters facilitated export of phenol and cytotoxic compounds from the cells, and maintained the intracellular drug concentration at low levels in order to maintain cell viability. This is the first study to shed light on the influence of phenol, a ubiquitous pollutant in wastewater, on the physiological characteristics of C. tropicalis SHC-03 and explore its tolerance mechanism to phenol stress.

\section{DATA AVAILABILITY STATEMENT}

The datasets generated for this study can be found in the Sequence files for all the treatment samples used in this study have been deposited at NCBI SRA with accession: PRJNA591802. 


\section{AUTHOR CONTRIBUTIONS}

MM, HW, QL, QC, and XZ conceived and designed the project. QL, HW, YP, ZZ, XK, XHu, and XHa performed the experiments. QL, HW, QX, XY, KZ, LZ, YG, XiLi, and XiaLi performed the data analysis. HW, QL, YP, and ZZ wrote the manuscript. MM, $\mathrm{BL}, \mathrm{EA}$, and GA revised the manuscript. All authors read and approved the final manuscript.

\section{FUNDING}

We gratefully acknowledge financial support from China Scholarship Council. This work was financially supported by the National Natural Science Foundation of China (No. 31570086), the 2011 Collaborative Innovation Center for Farmland Protection and Agricultural Product Safety in Sichuan Province, the Talent Introduction Fund of Sichuan Agricultural

\section{REFERENCES}

Adav, S. S., Chen, M. Y., Lee, D. J., and Ren, N. Q. (2007). Degradation of phenol by aerobic granules and isolated yeast Candida tropicalis. Biotechnol. Bioeng. 96, 844-852. doi: 10.1002/bit.21148

Aguilar-Uscanga, B., and Francois, J. M. (2003). A study of the yeast cell wall composition and structure in response to growth conditions and mode of cultivation. Lett. Appl. Microbiol. 37, 268-274. doi: 10.1046/j.1472-765x.2003. 01394.x

Anders, S., and Huber, W. (2010). Differential expression analysis for sequence count data. Genome Biol. 11:R106. doi: 10.1186/gb-2010-11-10-r106

Ashburner, M., Ball, C., Blake, J., Botstein, D., Butler, H., Cherry, J., et al. (2000). Gene ontology tool for the unification of biology. Nat. Genet. 25, 25-29. doi: $10.1038 / 75556$

Baba, M., Takeshige, K., Baba, N., and Ohsumi, Y. (1994). Ultrastructural analysis of the autophagic process in yeast: detection of autophagosomes and their characterization. J. Cell Biol. 124, 903-913. doi: 10.1083/jcb.124. 6.903

Baker, L. G., Specht, C. A., Donlin, M. J., and Lodge, J. K. (2007). Chitosan, the deacetylated form of chitin, is necessary for cell wall integrity in Cryptococcus neoformans. Eukaryot. Cell 6, 855-867. doi: 10.1128/EC.003 99-06

Banerjee, A., and Ghoshal, A. K. (2011). Phenol degradation performance by isolated Bacillus cereus immobilized in alginate. Int. Biodet. Biodeg. 65, $1052-$ 1060. doi: 10.1016/j.ibiod.2011.04.011

Bulik, D. A., Olczak, M., Lucero, H. A., Osmond, B. C., Robbins, P. W., and Specht, C. A. (2003). Chitin synthesis in Saccharomyces cerevisiae in response to supplementation of growth medium with glucosamine and cell wall stress. Eukaryot. Cell 2, 886-900. doi: 10.1128/ec.2.5.886-900.2003

Busca, G., Berardinelli, S., Resini, C., and Arrighi, L. (2008). Technologies for the removal of phenol from fluid streams: a short review of recent developments. J. Hazard. Mater. 160, 265-288. doi: 10.1016/j.jhazmat.2008. 03.045

Butler, G., Rasmussen, M. D., Lin, M. F., Santos, M. A., Sakthikumar, S., Munro, C. A., et al. (2009). Evolution of pathogenicity and sexual reproduction in eight Candida genomes. Nature 459, 657-662. doi: 10.1038/nature08064

Demand, J., Alberti, S., Patterson, C., and Hohfeld, J. (2001). Cooperation of a ubiquitin domain protein and an E3 ubiquitin ligase during chaperone/proteasome coupling. Curr. Biol. 11, 1569-1577. doi: 10.1016/s0960-9822(01)00487-0

Deshpande, M. V., O’Donnell, R., and Gooday, G. W. (1997). Regulation of chitin synthase activity in the dimorphic fungus Benjaminiella poitrasii by external osmotic pressure. FEMS Microbiol. Lett. 152, 327-332. doi: 10.1111/j.15746968.1997.tb10447.x
University (No. 01426100), and the Research Interest Training Program for Undergraduate Students of Sichuan Agricultural University (No. 2019337).

\section{ACKNOWLEDGMENTS}

We are particularly grateful to Z. Lewis Liu, Bioenergy Research Unit, NCAUR-ARS, U.S. Department of Agriculture (Peoria, IL, United States) for providing the mRNA control mix as reference mRNA in the qRT-PCR reactions.

\section{SUPPLEMENTARY MATERIAL}

The Supplementary Material for this article can be found online at: https://www.frontiersin.org/articles/10.3389/fmicb. 2020.00544/full\#supplementary-material

Doong, H., Rizzo, K., Fang, S., Kulpa, V., Weissman, A. M., and Kohn, E. C. (2003). CAIR-1/BAG-3 abrogates heat shock protein-70 chaperone complexmediated protein degradation: accumulation of poly-ubiquitinated Hsp90 client proteins. J. Biol. Chem. 278, 28490-28500. doi: 10.1074/jbc.M20968 2200

Dos Santos, S. C., Teixeira, M. C., Dias, P. J., and Sa-Correia, I. (2014). MFS transporters required for multidrug/multixenobiotic (MD/MX) resistance in the model yeast: understanding their physiological function through post-genomic approaches. Front. Physiol. 5:180. doi: 10.3389/fphys.2014. 00180

Florea, L., Song, L., and Salzberg, S. L. (2013). Thousands of exon skipping events differentiate among splicing patterns in sixteen human tissues. F1000Res. 2:188. doi: 10.12688/f1000research.2-188.v2

Gill, S. S., Anjum, N. A., Hasanuzzaman, M., Gill, R., Trivedi, D. K., Ahmad, I., et al. (2013). Glutathione and glutathione reductase: a boon in disguise for plant abiotic stress defense operations. Plant Physiol. Biochem. 70, 204-212. doi: 10.1016/j.plaphy.2013.05.032

Gourlay, C. W., and Ayscough, K. R. (2005). Identification of an upstream regulatory pathway controlling actin-mediated apoptosis in yeast. J. Cell Sci. 118, 2119-2132. doi: $10.1242 /$ jcs. 02337

Gu, H., Zhang, J., and Bao, J. (2015). High tolerance and physiological mechanism of Zymomonas mobilis to phenolic inhibitors in ethanol fermentation of corncob residue. Biotechnol. Bioeng. 112, 1770-1782. doi: 10.1002/bit.25603

Heipieper, H. J., Keweloh, H., and Rehm, H. J. (1991). Influence of phenols on growth and membrane permeability of free and immobilized Escherichia coli. Appl. Environ. Microbiol. 57, 1213-1217.

Horitsu, H., Yahashi, Y., Takamizawa, K., Kawai, K., Suzuki, T., and Watanabe, N. (1992). Production of xylitol from D-xylose by Candida tropicalis: optimization of production rate. Biotechnol. Bioeng. 40, 1085-1091. doi: 10.1002/bit. 260400912

Hossain, M. Z., Teixeira da Silva, J. A., and Fujita, M. (2006). "Differential roles of glutathione S-transferase in oxidative stress modulation," in Floriculture, Ornamental and Plant Biotechnology, ed. J. A. Teixeira da Silva, (London: Global Science Books Ltd), 108-116.

Ibraheem, O., and Ndimba, B. K. (2013). Molecular adaptation mechanisms employed by ethanologenic bacteria in response to lignocellulose-derived inhibitory compounds. Int. J. Biol. Sci. 9, 598-612. doi: 10.7150/ijbs. 6091

Jiang, Y., Wen, J., Li, H., Yang, S., and Hu, Z. (2005). The biodegradation of phenol at high initial concentration by the yeast Candida tropicalis. Biochem. Eng. J. 24, 243-247. doi: 10.1016/j.bej.2005.02.016

Kanehisa, M., Goto, S., Kawashima, S., Okuno, Y., and Hattori, M. (2004). The KEGG resource for deciphering the genome. Nucleic Acids Res. 32, D277-280. doi: 10.1093/nar/gkh063 
Klaunig, J. E., Wang, Z., Pu, X., and Zhou, S. (2011). Oxidative stress and oxidative damage in chemical carcinogenesis. Toxicol. Appl. Pharmacol. 254, 86-99. doi: 10.1016/j.taap.2009.11.028

Krug, M., Ziegler, H., and Straube, G. (1985). Degradation of phenolic compounds by the yeast Candida tropicalis HP 15. I. Physiology of growth and substrate utilization. J. Basic Microbiol. 25, 103-110. doi: 10.1002/jobm.3620250206

Kupiec, M., Byers, B., and Esposito, R. (1997). "Meiosis and sporulation in Saccharomyces cerevisiae," in The Molecular and Cellular Biology of the Yeast Saccharomyces cerevisiae, eds J. Pringle, J. Broach, and E. Jones, (New York, NY: Cold Spring Harbor), 889-1036.

Kurihara, T., Ueda, M., Okada, H., Kamasawa, N., Naito, N., Osumi, M., et al. (1992). Beta-oxidation of butyrate, the short-chain-length fatty acid, occurs in peroxisomes in the yeast Candida tropicalis. J. Biochem. 111, 783-787. doi: 10.1093/oxfordjournals.jbchem.a123836

Kurosawa, K., Laser, J., and Sinskey, A. J. (2015). Tolerance and adaptive evolution of triacylglycerol-producing Rhodococcus opacus to lignocellulosederived inhibitors. Biotechnol. Biofuels 8:76. doi: 10.1186/s13068-0150258-3

Lanneau, D., Wettstein, G., Bonniaud, P., and Garrido, C. (2010). Heat shock proteins: cell protection through protein triage. ScientificWorldJournal 10, 1543-1552. doi: 10.1100/tsw.2010.152

Lima, C. F., Fernandes-Ferreira, M., and Pereira-Wilson, C. (2006). Phenolic compounds protect HepG2 cells from oxidative damage: relevance of glutathione levels. Life Sci. 79, 2056-2068. doi: 10.1016/j.lfs.2006.06.042

Lin, C. P., Kim, C., Smith, S. O., and Neiman, A. M. (2013). A highly redundant gene network controls assembly of the outer spore wall in S. cerevisiae. PLoS Genet. 9:e1003700. doi: 10.1371/journal.pgen.1003700

Liu, Z. L., and Slininger, P. J. (2007). Universal external RNA controls for microbial gene expression analysis using microarray and qRT-PCR. J. Microbiol. Methods 68, 486-496. doi: 10.1016/j.mimet.2006.10.014

Long, Y., Yang, S., Xie, Z., and Cheng, L. (2014). Identification and characterization of phenol hydroxylase from phenol-degrading Candida tropicalis strain JH8. Can. J. Microbiol. 60, 585-591. doi: 10.1139/cjm-2014-0417

Ma, M., and Liu, Z. L. (2010). Comparative transcriptome profiling analyses during the lag phase uncover YAP1, PDR1, PDR3, RPN4, and HSF1 as key regulatory genes in genomic adaptation to the lignocellulose derived inhibitor HMF for Saccharomyces cerevisiae. BMC Genomics 11:660. doi: 10.1186/1471-216411-660

Mahgoub, S., Abdelbasit, H., and Abdelfattah, H. (2014). Removal of phenol and zinc by Candida isolated from wastewater for integrated biological treatment. Desalin. Water Treat. 53, 3381-3387. doi: 10.1080/19443994.2014.93 4113

Mao, X., Cai, T., Olyarchuk, J. G., and Wei, L. (2005). Automated genome annotation and pathway identification using the KEGG Orthology (KO) as a controlled vocabulary. Bioinformatics 21, 3787-3793. doi: 10.1093/ bioinformatics/bti430

Masutomi, K., Possemato, R., Wong, J. M., Currier, J. L., Tothova, Z., Manola, J. B., et al. (2005). The telomerase reverse transcriptase regulates chromatin state and DNA damage responses. Proc. Natl. Acad. Sci. U.S.A. 102, 8222-8227. doi: 10.1073/pnas.0503095102

Matjie, R. H., and Engelbrecht, R. (2007). Selective removal of dissolved silicon and aluminium ions from gas liquor by hydrometallurgical methods. Hydrometallurgy 85, 172-182. doi: 10.1016/j.hydromet.2006.08.012

Mayer, M. L., Gygi, S. P., Aebersold, R., and Hieter, P. (2001). Identification of $\mathrm{RFC}(\mathrm{Ctf18p}, \mathrm{Ctf} 8 \mathrm{p}, \mathrm{Dcclp})$ an alternative RFC complex required for sister chromatid cohesion in S. cerevisiae. Mol. Cell 7, 959-970. doi: 10.1016/s10972765(01)00254-4

Mishra, V. K., and Kumar, N. (2017). Microbial degradation of phenol: a review. J. Water Pollut. Purif. Res. 4, 17-22. doi: 10.1504/IJEP.2008.016895

Neiman, A. M. (2011). Sporulation in the budding yeast Saccharomyces cerevisiae. Genetics 189, 737-765. doi: 10.1534/genetics.111.127126

Nunes, P. A., Tenreiro, S., and Sa-Correia, I. (2001). Resistance and adaptation to quinidine in Saccharomyces cerevisiae: role of QDR1 (YIL120w), encoding a plasma membrane transporter of the major facilitator superfamily required for multidrug resistance. Antimicrob. Agents Chemother. 45, 1528-1534. doi: 10.1128/AAC.45.5.1528-1534.2001

Obeng, E. A., Carlson, L. M., Gutman, D. M., Harrington, W. J. Jr., and Lee, K. P. (2006). Proteasome inhibitors induce a terminal unfolded protein response in multiple myeloma cells. Blood 107, 4907-4916. doi: 10.1182/blood-2005-083531

Oku, M., Nishimura, T., Hattori, T., Ano, Y., Yamashita, S., and Sakai, Y. (2006). Role of Vac8 in formation of the vacuolar sequestering membrane during micropexophagy. Autophagy 2, 272-279. doi: 10.4161/auto.3135

Pammer, M., Briza, P., Ellinger, A., Schuster, T., Stucka, R., Feldmanns, H., et al. (1992). DIT101 (CSD2, CAL1), a cell cycle-regulated yeast gene required for synthesis of chitin in cell walls and chitosan in spore walls. Yeast 8, 1089-1099. doi: $10.1002 /$ yea. 320081211

Perrone, G. G., Tan, S. X., and Dawes, I. W. (2008). Reactive oxygen species and yeast apoptosis. Biochim. Biophys. Acta 1783, 1354-1368. doi: 10.1016/j.bbamcr. 2008.01.023

Pinto, R. T. P., Lintomen, L., Luz, L. F. L., and Wolf-Maciel, M. R. (2005). Strategies for recovering phenol from wastewater: thermodynamic evaluation and environmental concerns. Fluid Phase Equilib. 228-229, 447-457. doi: 10. 1016/j.fluid.2004.09.005

Rowe, L. A., Degtyareva, N., and Doetsch, P. W. (2008). DNA damage-induced reactive oxygen species (ROS) stress response in Saccharomyces cerevisiae. Free Radic. Biol. Med. 45, 1167-1177. doi: 10.1016/j.freeradbiomed.2008.07.018

Ruiz-Herrera, J., Martıinez, A. I., and Sentandreu, R. (2002). Determination of the stability of protein pools from the cell wall of fungi. Res. Microbiol. 153, 373-378. doi: 10.1016/s0923-2508(02)01335-9

Sa-Correia, I., dos Santos, S. C., Teixeira, M. C., Cabrito, T. R., and Mira, N. P. (2009). Drug:H+ antiporters in chemical stress response in yeast. Trends Microbiol. 17, 22-31. doi: 10.1016/j.tim.2008.09.007

Sampaio, J. P. (1999). Utilization of low molecular weight aromatic compounds by heterobasidiomycetous yeasts: taxonomic implications. Can. J. Microbiol. 45, 491-512. doi: 10.1139/w99-020

Schneiter, R., Guerra, C., Lampl, M., Tatzer, V., Zellnig, G., Klein, H., et al. (2000). A novel cold-sensitive allele of the rate-limiting enzyme of fatty acid synthesis, acetyl coenzyme A carboxylase, affects the morphology of the yeast vacuole through acylation of Vac8p. Mol. Cell. Biol. 20, 2984-2995. doi: 10.1128/mcb. 20.9.2984-2995.2000

Senft, D., and Ronai, Z. A. (2015). UPR, autophagy, and mitochondria crosstalk underlies the ER stress response. Trends Biochem. Sci. 40, 141-148. doi: 10.1016/ j.tibs.2015.01.002

Suzuki, K., and Ohsumi, Y. (2007). Molecular machinery of autophagosome formation in yeast, Saccharomyces cerevisiae. FEBS Lett. 581, 2156-2161. doi: 10.1016/j.febslet.2007.01.096

Teixeira, M. C., Monteiro, P. T., Guerreiro, J. F., Goncalves, J. P., Mira, N. P., dos Santos, S. C., et al. (2014). The YEASTRACT database: an upgraded information system for the analysis of gene and genomic transcription regulation in Saccharomyces cerevisiae. Nucleic Acids Res. 42, D161-166. doi: 10.1093/nar/ gkt1015

Teixeira, M. C., Raposo, L. R., Mira, N. P., Lourenco, A. B., and Sa-Correia, I. (2009). Genome-wide identification of Saccharomyces cerevisiae genes required for maximal tolerance to ethanol. Appl. Environ. Microbiol. 75, 5761-5772. doi: 10.1128/AEM.00845-09

Varma, R. J., and Gaikwad, B. G. (2009). Biodegradation and phenol tolerance by recycled cells of Candida tropicalis NCIM 3556. Int. Biodeter. Biodegr. 63, 539-542. doi: 10.1016/j.ibiod.2009.01.001

Walter, S., and Buchner, J. (2002). Molecular chaperones-cellular machines for protein folding. Angew. Chem. Int. Ed. Engl. 41, 1098-1113.

Wang, C. W., and Klionsky, D. J. (2003). The molecular mechanism of autophagy. Mol. Med. 9, 65-76. doi: 10.1007/BF03402040

Wang, S., Li, H., Fan, X., Zhang, J., Tang, P., and Yuan, Q. (2015). Metabolic responses in Candida tropicalis to complex inhibitors during xylitol bioconversion. Fungal Genet. Biol. 82, 1-8. doi: 10.1016/j.fgb.2015.04.022

Yang, J., Ding, M. Z., Li, B. Z., Liu, Z. L., Wang, X., and Yuan, Y. J. (2012). Integrated phospholipidomics and transcriptomics analysis of Saccharomyces cerevisiae with enhanced tolerance to a mixture of acetic acid, furfural, and phenol. OMICS 16, 374-386. doi: 10.1089/omi.2011.0127

Yao, R., Zhang, Z., An, X., Bucci, B., Perlstein, D. L., Stubbe, J., et al. (2003). Subcellular localization of yeast ribonucleotide reductase regulated by the DNA replication and damage checkpoint pathways. Proc. Natl. Acad. Sci. U.S.A. 100, 6628-6633. doi: 10.1073/pnas.1131932100

Yi, X., Gu, H., Gao, Q., Liu, Z. L., and Bao, J. (2015). Transcriptome analysis of Zymomonas mobilis ZM4 reveals mechanisms of tolerance and detoxification 
of phenolic aldehyde inhibitors from lignocellulose pretreatment. Biotechnol. Biofuels 8:153. doi: 10.1186/s13068-015-0333-9

Yoneda, A., Henson, W. R., Goldner, N. K., Park, K. J., Forsberg, K. J., Kim, S. J., et al. (2016). Comparative transcriptomics elucidates adaptive phenol tolerance and utilization in lipid-accumulating Rhodococcus opacus PD630. Nucleic Acids Res. 44, 2240-2254. doi: 10.1093/nar/gk w055

Zhou, L., Cheng, D., Wang, L., Gao, J., Zhao, Q., Wei, W., et al. (2017). Comparative transcriptomic analysis reveals phenol tolerance mechanism of evolved Chlorella strain. Bioresour. Technol. 227, 266-272. doi: 10.1016/j. biortech.2016.12.059
Conflict of Interest: The authors declare that the research was conducted in the absence of any commercial or financial relationships that could be construed as a potential conflict of interest.

Copyright (๑) 2020 Wang, Li, Peng, Zhang, Kuang, Hu, Ayepa, Han, Abrha, Xiang, Yu, Zhao, Zou, Gu, Li, Li, Chen, Zhang, Liu and Ma. This is an open-access article distributed under the terms of the Creative Commons Attribution License (CC BY). The use, distribution or reproduction in other forums is permitted, provided the original author(s) and the copyright owner(s) are credited and that the original publication in this journal is cited, in accordance with accepted academic practice. No use, distribution or reproduction is permitted which does not comply with these terms. 